\title{
Analytical Evaluation of Mesoscale Fluxes and Pressure Field
}

\author{
MARINA BALDI ${ }^{\mathrm{a}, \mathrm{b}}$, GIOVANNI A. DALU ${ }^{\mathrm{a}, \mathrm{b}}$, ROGER A. PIELKE SR. ${ }^{\mathrm{b}}$ and \\ FRANCESCO MENEGUZZO ${ }^{\mathrm{c}}$ \\ ${ }^{\mathrm{a}}$ Institute of Biometeorology - IBIMET-CNR, via Nizza 128, 00198 Rome, Italy; ${ }^{\mathrm{b}}$ Department of \\ Atmospheric Science - Colorado State University, Fort Collins, CO 80523, U.S.A.; ${ }^{\mathrm{c}}$ Institute of \\ Biometeorology - IBIMET-CNR, via G. Caproni, 8, 50145 Firenze, Italy
}

Received 11 June 2003; accepted in revised form 20 January 2004

\begin{abstract}
Terrain in natural areas is never homogeneous: there may be a variety of vegetation types and patches of vegetated and unvegetated areas which can modify the mesoscale atmospheric flow. Moreover, horizontal thermal inhomogeneities in the planetary boundary layer are a well known source of mesoscale circulation systems such as land and sea breezes, mountain-valley winds, and urban heat island circulations. Since those phenomena are not resolved in regional scale numerical models, therefore an analytic procedure able to evaluate the relative importance of mesoscale and turbulent heat fluxes associated with surface thermal heterogeneities is of crucial importance in the optic of developing a parameterization of mesoscale effects generated by these heterogeneities for use in larger scale models. In the present paper we analyze how small a horizontal variation in surface heating can be and still produce a significant mesoscale circulation, how the heat and momentum fluxes associated to mesoscale flows can penetrate deeply into the mid-troposphere, and how they modify tropospheric relevant climate parameters, such as the atmospheric static stability. In addition, we evaluate the terms of the pressure gradient force, nonlinear and linear, non-hydrostatic and hydrostatic, as function of time and space scales of the mesoscale flow. The present paper is mainly a review of analytical results, the numerical comparison and verification using RAMS is in progress.
\end{abstract}

Key words: geopotential, heat flux, hydrostatic flow, mesoscale circulation, momentum flux, nonhydrostatic flow

\section{Introduction}

Terrain in the real world is almost never uniform, for instance, in natural areas there may be a variety of vegetation types and patches of vegetated or unvegetated areas which can modify the mesoscale atmospheric flow. Horizontal thermal inhomogeneities in the planetary boundary layer are a well known source of mesoscale circulation systems. Thermally-forced mesoscale systems such as land and sea breezes, mountain-valley winds, and urban heat island circulations have been the subject of many studies: [1-9]. Some thermally-generated mesoscale circulations 
are due to horizontal inhomogeneities in ground wetness, vegetation cover, snow cover, cloud cover as studied by many authors, e.g. [8, 10-13]. In addition there are also anthropogenic modifications of soil and vegetation, such as irrigated or non-irrigated fields, crops at different stages of growth, inhabited areas, and so on [14-17]. Such thermal inhomogeneities may extend from few square meters to hundreds or even thousands of square kilometers.

A number of studies, observational, numerical and analytical, have been made of these physiographically forced circulations as in $[10 ; 12,18-21]$.

There is convincing observational and modeling evidence, that mesoscale fluxes that result from landscape heterogeneity can often be as large as and larger than turbulent fluxes, as well as have a different vertical distribution than the turbulent fluxes averaged over the scale of a GCM or NWP grid increment. Examples of studies that document the modification of atmospheric boundary layer structure, and/or the development of mesoscale flow due to land surface inhomogeneity are reported in [1-3, 9, 22-30]. A number of these papers are summarized in Cotton and Pielke [3]. These mesoscale fluxes have substantial coherent structure such that they are predictable features as discussed in [31-33]. Zeng and Pielke [32] concluded that the important controls on mesoscale fluxes include planetary boundary layer depth, horizontal size of the surface heat patches, the potential temperature difference between different patches, the surface sensible moisture and momentum fluxes, and height above the surface.

During the last decade or so, procedures to represent landscape heterogeneity within a larger-scale area, such as a general circulation model (GCM) or Numerical Weather Prediction (NWP) grid cell, have focused on a summation of surface fluxes within that area, proportionally weighted by the fluxes from each land surface type. Examples of this approach are reported in [1,34-41].

Glendening and Lin [42] and Lin and Glendening [43] show that perturbations induced by small scale landscape variability (few kilometer wavelength) have an impact on the atmospheric surface layer. Gopalakrishna et al. [44], Gopalakrishna and Avissar [45], and Roy and Avissar [46] focus on landscape features up to tens of kilometers, which have an impact on the atmospheric CBL, but can also penetrate into the free atmosphere just above it. We show that the landscape variability between tens of kilometer and one Rossby radius generate perturbations which can penetrate deeply into the free troposphere and can modify the basic parameters of the large scale flow.

Subgrid-scale parameterization is of considerable importance in regional and larger scale models because these models seldom have more than a few grid points within a Rossby radius, yet the mesoscale flow driven by thermal horizontal inhomogeneities in the Convective Boundary Layer ( $C B L)$ may be significant. Therefore mesoscale effects need to be introduced in parametric form into those large scale models, and in particular it is important to determine how small a horizontal variation in surface heating can be and still produce a significant mesoscale circulation. Wang [47] gives an evaluation of the mesoscale flow for a stochastic 
distribution of thermal inhomogeneities. Lyn et al. [48] and Pielke et al. [49] present a new procedure to parameterize mesoscale fluxes resulting from landscape patches.

Hydrostatic and linear approximations to the equations which describe the atmospheric flow are frequently made in order to simplify their integration in time. Pielke [6] describes the use and applications of these two solution techniques. The hydrostatic approximation is useful since, when it accurately describes atmospheric flow, the pressure field is directly diagnosed from the instantaneous temperature field. The use of the linear approximation permits analytically exact solutions. Moreover, the linear approximation is a realistic representation of atmospheric flows when nearly linear forcing occurs.

Non-hydrostatic versus hydrostatic flow has been extensively studied theoretically and numerically. In geophysics, there are many flows where these differences are relevant, as shown in [50, 51]. One obvious application is the lee-wave, where the aspect ratio is order one and the time scale is strictly related to the BruntVäisälä frequency [52, 53], or more recent work as [54]. There are studies of the unstable convective boundary layer and thermocline which show that non-hydrostatic terms are important where thermals are present [55-57]. Non-hydrostatic effects are also important in cloud dynamics: Cotton and Anthes [58].

Song et al. [59] proposed a procedure to decompose a set of atmospheric equations into hydrostatic and non-hydrostatic components, while Weidman and Pielke [67] described a technique to segment linear and nonlinear terms. Using the modeling framework represented in [60], we apply these two methodologies in order to develop an improved understanding of the role of hydrostatic and non-hydrostatic, and linear and nonlinear contributions to the horizontal pressure gradient force associated with thermally forced mesoscale flows.

\section{Environmental Parameters}

The environmental parameters used in the present analytical model are set as follows:

Brunt-Väisälä frequency,

$$
\begin{array}{r}
\Theta_{z}=1 \text { to } 5[\mathrm{~K} / \mathrm{km}] \quad \mathrm{b}=\mathrm{g} \frac{\theta}{\Theta} ; \\
N=\left(g \frac{\Theta_{z}}{\Theta}\right)^{\frac{1}{2}}=3 \times 10^{-3} \text { to } 2 \times 10^{-2}\left[\mathrm{~s}^{-1}\right] ;
\end{array}
$$

$\theta=$ potential temperature perturbation,

$\Theta=$ environment potential temperature,

$\Theta_{z}=$ vertical gradient of $\Theta$. 
Coriolis parameter

$$
f=2 \omega_{E} \sin (\text { lat })=10^{-4}\left[\mathrm{~s}^{-1}\right] ; \quad \omega_{0}=1 \text { to } 100\left[\frac{2 \pi}{\text { day }}\right] ;
$$

$\omega_{0}=$ pulsation of the forcing,

$\omega_{E}=(2 \pi /$ day $)=$ angular velocity of the Earth.

Diffusion coefficient

$$
\begin{aligned}
& K=10 \text { to } 100\left[\mathrm{~m}^{2} \mathrm{~s}^{-1}\right] ; \\
& \lambda=1 \text { to } 100\left[\text { day }^{-1}\right] ; \quad U=0 \text { to } 10\left[\mathrm{~m} \mathrm{~s}^{-1}\right] ;
\end{aligned}
$$

$\lambda^{-1}=$ lifetime of the mesoscale flow,

$\lambda=$ Rayleigh friction coefficient, i.e., a bulk dissipation which represents frictional losses at low wavenumbers, and $K$ is the diffusion coefficient that accounts for the losses at high wavenumbers. In nature during the day, within the convective atmospheric boundary layer the diffusion process is very active and the diffusion coefficient $K$ is very high. In the free atmosphere and during the night the diffusion processes are weak and the diffusion coefficient $K$ is low [61].

\section{The Mesoscale Forcing}

The mesoscale flow is driven by the buoyancy gradient generated by the diabatic source, $Q$ :

$$
Q=Q_{0} q(t) r(x, z),
$$

where $q(t)$ is its time behavior and $r(x, z)$ its spatial distribution. The diabatic perturbation of the buoyancy, $B$, directly induced by the heat source, $Q$, is

$$
B=Q_{0} r(x, z) \int_{0}^{t} q\left(t^{\prime}\right) \mathrm{d} t^{\prime}
$$

\section{Linear Formulation}

We define the linear operator $\mathcal{L}$, and formally its inverse $\mathcal{L}^{-1}$ and its square $\mathcal{L}^{2}$ :

$$
\mathcal{L} \equiv\left(\frac{\partial}{\partial t}+\lambda+U \frac{\partial}{\partial x}-K \nabla^{2}\right)
$$




$$
\mathcal{L}^{-1} \mathcal{L} f(x, z, t)=f(x, z, t) ; \quad \mathcal{L} \mathcal{L} f(x, z, t)=\mathscr{L}^{2} f(x, z, t) .
$$

We define the Laplacian operator $\nabla^{2}$ and formally the inverse Laplacian operator $\nabla^{-2}$

$$
\nabla^{2} \equiv \frac{\partial^{2}}{\partial x^{2}}+\frac{\partial^{2}}{\partial z^{2}} ; \quad \nabla^{-2} \nabla^{2} f(x, z, t)=f(x, z, t)
$$

We define the Fourier transform $\mathcal{F}\{f(x, z, t)\}=\tilde{f}(k, v, \omega)$, and its inverse

$$
\mathcal{F}^{-1}\{\tilde{f}(k, v, \omega)\}=f(x, z, t) .
$$
$\tilde{\mathcal{L}}^{2}$ are:

Then the Fourier transforms of the operator $\tilde{\mathscr{L}}$, its inverse $\tilde{\mathscr{L}}^{-1}$ and its square

$$
\begin{aligned}
& \tilde{\mathscr{L}} \equiv\left[\lambda+K\left(k^{2}+v^{2}\right)\right]+i(\omega+k U)=D+i \Omega \\
& \tilde{\mathscr{L}}^{-1}=\frac{D-i \Omega}{D^{2}+\Omega^{2}} \\
& \tilde{\mathscr{L}}^{2}=D^{2}-\Omega^{2}+2 i \Omega D \\
& D=\lambda+K\left(k^{2}+v^{2}\right) ; \quad \Omega=(\omega+k U) .
\end{aligned}
$$

In Equation (8), $\tilde{\mathscr{L}}$ is a complex pulsation where the pulsation of $\omega$ is corrected by the large scale advection, dissipation and diffusion.

Indicating with the superscript $L$ Linear, the non-hydrostatic primitive equations are:

$$
\begin{aligned}
& \tilde{\mathscr{L}} u^{L}-f v^{L}+\phi_{x}{ }^{L}=0 ; ; \quad \tilde{\mathscr{L}} v^{L}+f u^{L}=0 ; ; \quad \tilde{\mathcal{L}} w^{L}+\phi_{z}{ }^{L}=b^{L}(9) \\
& \tilde{\mathscr{L}} b^{L}+N^{2} w^{L}+B_{x} w^{L}=Q ; ; \quad u_{x}^{L}+w_{z}^{L}=0 .
\end{aligned}
$$

\subsection{IMPACT OF THE LARGE SCALE WIND ON THE MESOSCALE FLOW}

If $f(x, z, t)$ is the dynamical response to a periodic forcing $Q(x, z, t)$ through the operator $\mathcal{L}$ :

$$
\mathcal{L} f(x, z, t)=Q(x, z, t)=Q_{0} \sin (\omega t+k x+v z) .
$$


Then, in the presence of large scale advection $U \neq 0$, but in the absence of dissipation and diffusion $D=0$, there is an attenuation of the response $f(x, z, t)$ :

$$
\begin{array}{r}
f(x, z, t)=-\frac{Q_{0} \cos (\omega t+k x+v z)}{(\omega+k U)}= \\
\frac{Q_{0} \sin \left(\omega t+k x+v z-\frac{\pi}{2}\right)}{(\omega+k U)} .
\end{array}
$$

While, in the presence of large-scale advection $U \neq 0$ and in the presence of dissipation and diffusion $D \neq 0$ there is an attenuation and a phase shift of the response

$$
\frac{D Q_{0} \sin (\omega t+k x+v z)-\Omega Q_{0} \cos (\omega t+k x+v z)}{D^{2}+\Omega^{2}} .
$$

Figure 1 shows the mesoscale response as a function of the wavenumber for different values of the large scale flow and diffusion coefficient. The ratio betwen the vertical wavenumber and the horizontal wavenumber squared versus the horizontal square number of the in-phase and of the out-of-phase wave, respectively, is shown in upper panels; where the vertical wavenumber squared is negative, the mesoscale response in propagating waves. In the lower panels, there is the amplitute of the vertical velocity in meter per second of the in-phase and of the out-of-phase wave, respectively. The amplitude of the out-of-phase wave is generally smaller than the amplitude of the in-phase wave.

\subsection{LIFETIME OF THE MESOSCALE FLOW}

If $f(x, z, t)$ is the dynamical response to an impulsive forcing in the presence of dissipation and diffusion and in the absence of large scale flow, $U=0$ and $D \neq$ 0 ,

$$
\mathcal{L} f(x, z, t)=Q(x, z, t)=Q_{0} \sin (k x+v z)[\mathrm{He}(\mathrm{t})-\mathrm{He}(\mathrm{t}-\mathrm{T})] .
$$

He is the Heaviside step function: $[\mathrm{He}(\mathrm{t})-\mathrm{He}(\mathrm{t}-\mathrm{T})]=1$ for $0 \leq t<T$, and $T$ is the duration of the impulse. If $\mathrm{s}$ is the Laplace transform of the time and $\hat{f}(x, z, s)$ is Laplace transform of $f(x, z, t)$, then

$$
(s+D) \hat{f}(x, z, s)=Q_{0} \sin (k x+v z) \frac{1}{s}[1-\exp (-T s)],
$$




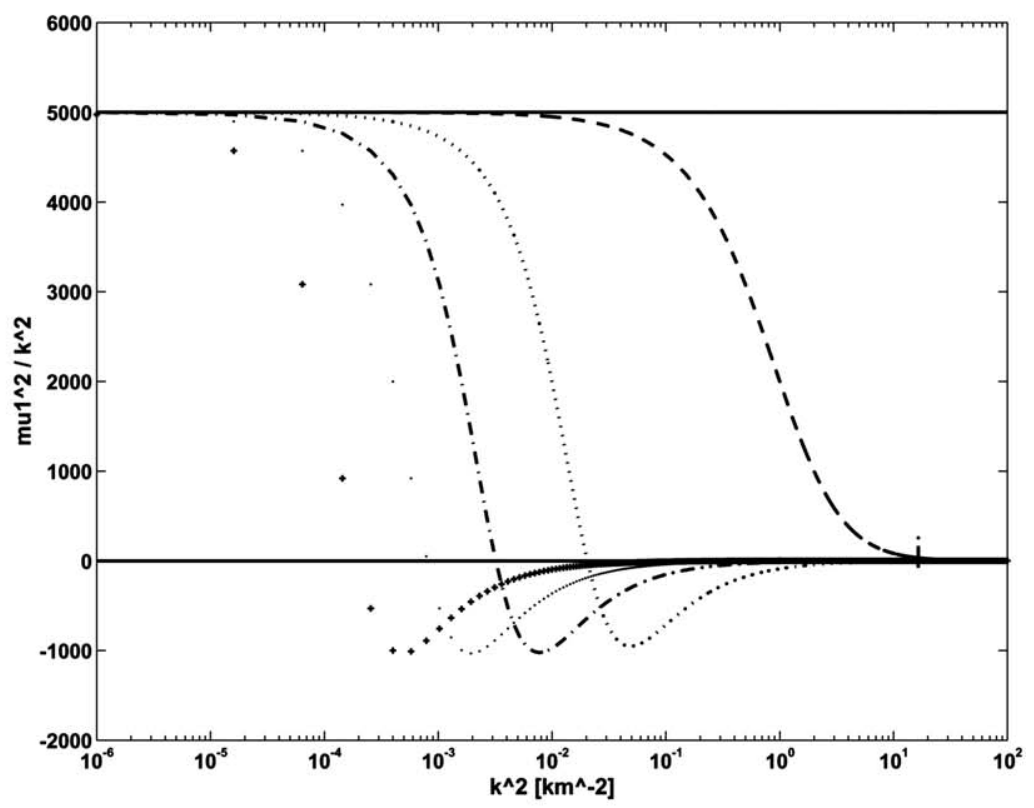

a.

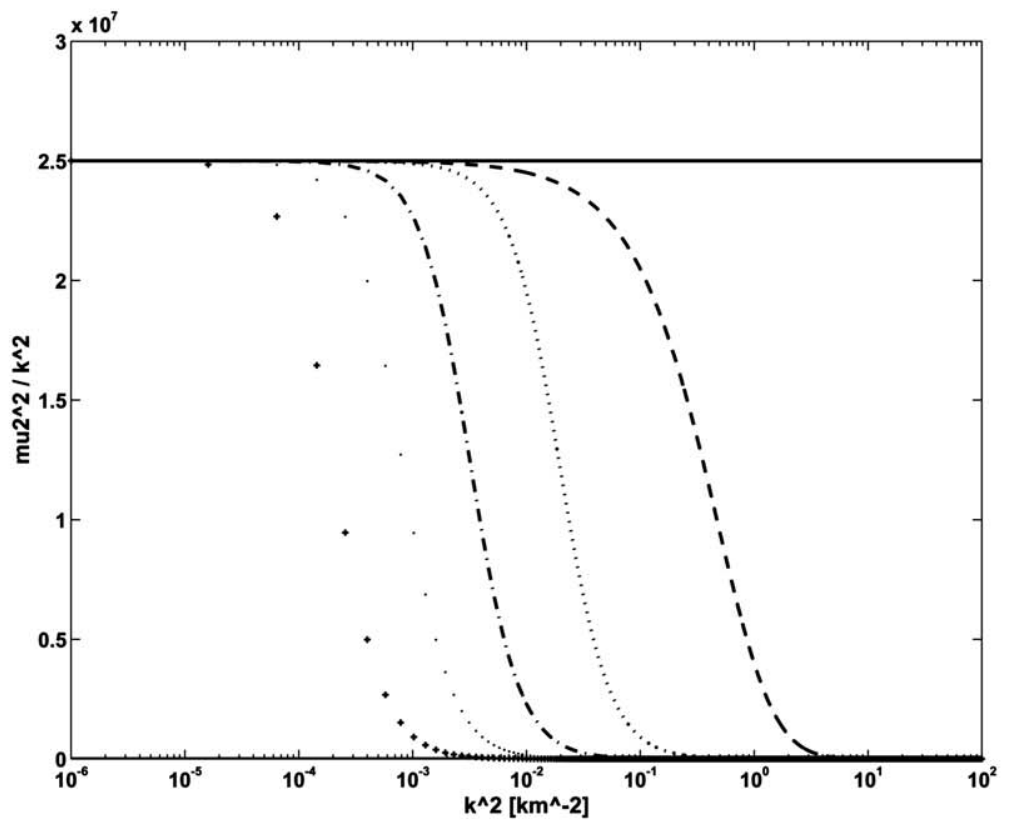

b.

Figure 1. Mesoscale response as a function of the horizontal wavenumber $k$ for different values of the large scale flow $U$ and diffusion coefficient $K . \mu_{1}$ and $\mu_{2}$ are the vertical wavenumber of the in-phase and of the out-of-phase wave, respectively, upper panels. Amplitude of the vertical velocity in meters per second of the in-phase and of the out-of-phase wave, respectively, lower panels. 


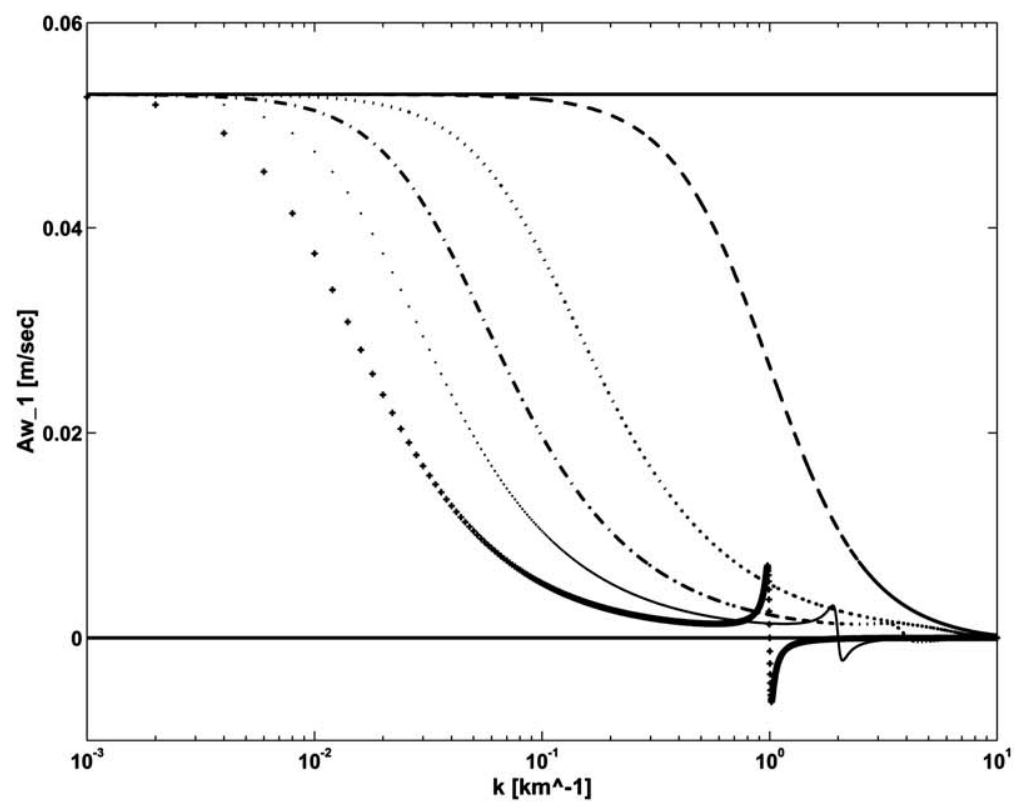

c.

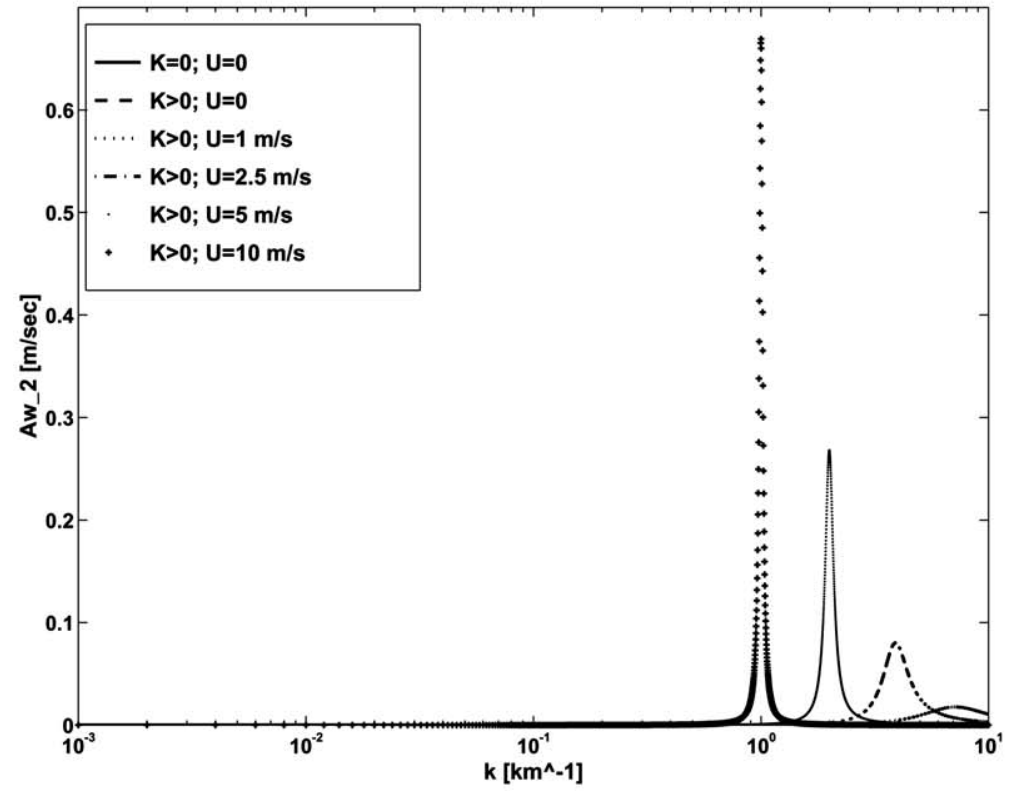

d.

Figure 1. Continued. 


$$
\begin{gathered}
f(x, z, t)=\tau Q_{0} \sin (k x+v z) \\
\left\{\operatorname{He}(\mathrm{t})\left[1-\exp \left(-\frac{\mathrm{t}}{\tau}\right)\right]-\operatorname{He}(\mathrm{t}-\mathrm{T})\left[1-\exp \left(-\frac{\mathrm{t}-\mathrm{T}}{\tau}\right)\right]\right\} \\
\text { when } t>T \text { then } \\
f(x, z, t)=\tau Q_{0} \sin (k x+v z)\left[\exp \left(-\frac{t-T}{\tau}\right)-\exp \left(-\frac{t}{\tau}\right)\right] \\
\tau=\frac{1}{\operatorname{Re}\{\tilde{\mathscr{L}}\}}=\frac{1}{D}=\frac{1}{\lambda+K\left(k^{2}+v^{2}\right)} .
\end{gathered}
$$

When the forcing ends, the flow decays with a lifetime $\tau$. This result can be generalized using the Shifting theorem in the Laplace transform and the Faltung theorem in the inverse Laplace transform [62].

Figure 2 shows the growth in time of the horizontal scale, $R(t)$, of the seabreeze flow as function of PBL, $h(t)$, for different values of friction $\lambda$. When $\lambda \ll f$, the mesoscale flow grows and decays through a series of gravity-inertia waves.

\subsection{THE LINEAR STREAMFUNCTION EQUATION}

From the primitive equations, we derive the non-hydrostatic equation for the streamfunction $\psi$.

The non-hydrostatic approximation can be made when: $\mathcal{L}^{2} \ll N^{2}$

$$
\left(\mathscr{L}+f^{2}\right) \frac{\partial^{2} \psi^{L}}{\partial z^{2}}+\left(\mathcal{L}+N^{2}\right) \frac{\partial^{2} \psi^{L}}{\partial x^{2}}=-\frac{\partial Q}{\partial x} .
$$

From the streamfunction equation, the horizontal scale of the mesoscale flow, the Rossby radius, is as in [65].

$$
R_{0}=h_{0} \sqrt{\frac{N^{2}+\mathcal{L}^{2}}{f^{2}+\mathcal{L}^{2}}} .
$$

When the vertical wavenumber, $\mu_{1}$, is real, mesoscale perturbations are trapped and spacially confined, while when $\mu_{1}$ is complex the perturbation propagates into the mid-troposphere:

$$
\mu_{1}^{2}=k_{0}^{2}\left[\frac{N^{2}+\mathscr{L}^{2}}{f^{2}+\mathscr{L}^{2}}\right]=k_{0}^{2}\left[\frac{b+i c}{a+i c}\right]
$$



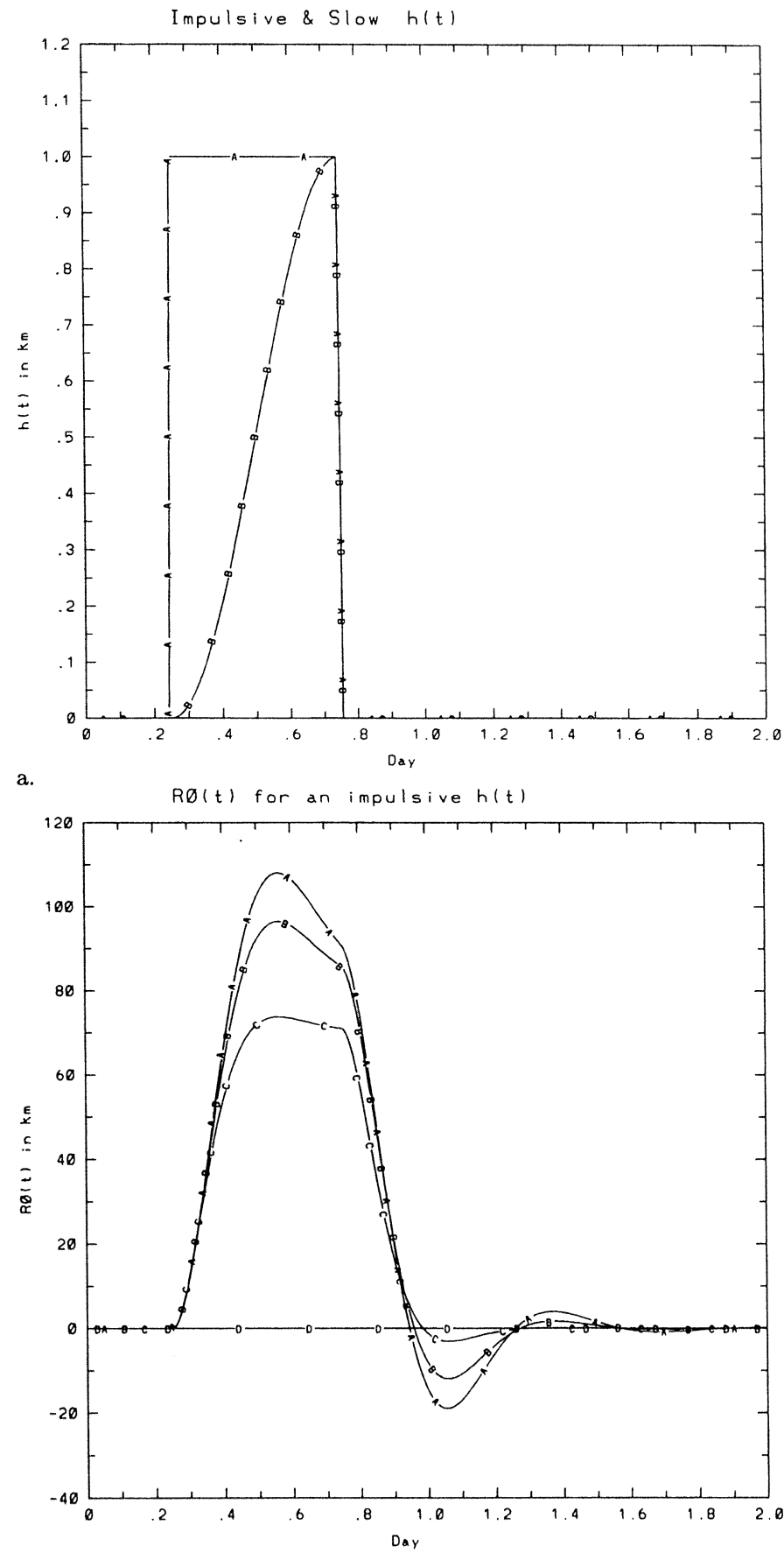

b.

Figure 2. Growth of the horizontal scale of the flow, $R(t)$, as a function of PBL depth, $h(t)$ panel (a), for different values of friction $\lambda$. (b) For a slow growing convective boundary layer, and (c) for a fast growing convective boundary layer. 
Analytical Evaluation of Mesoscale Fluxes and Pressure Field

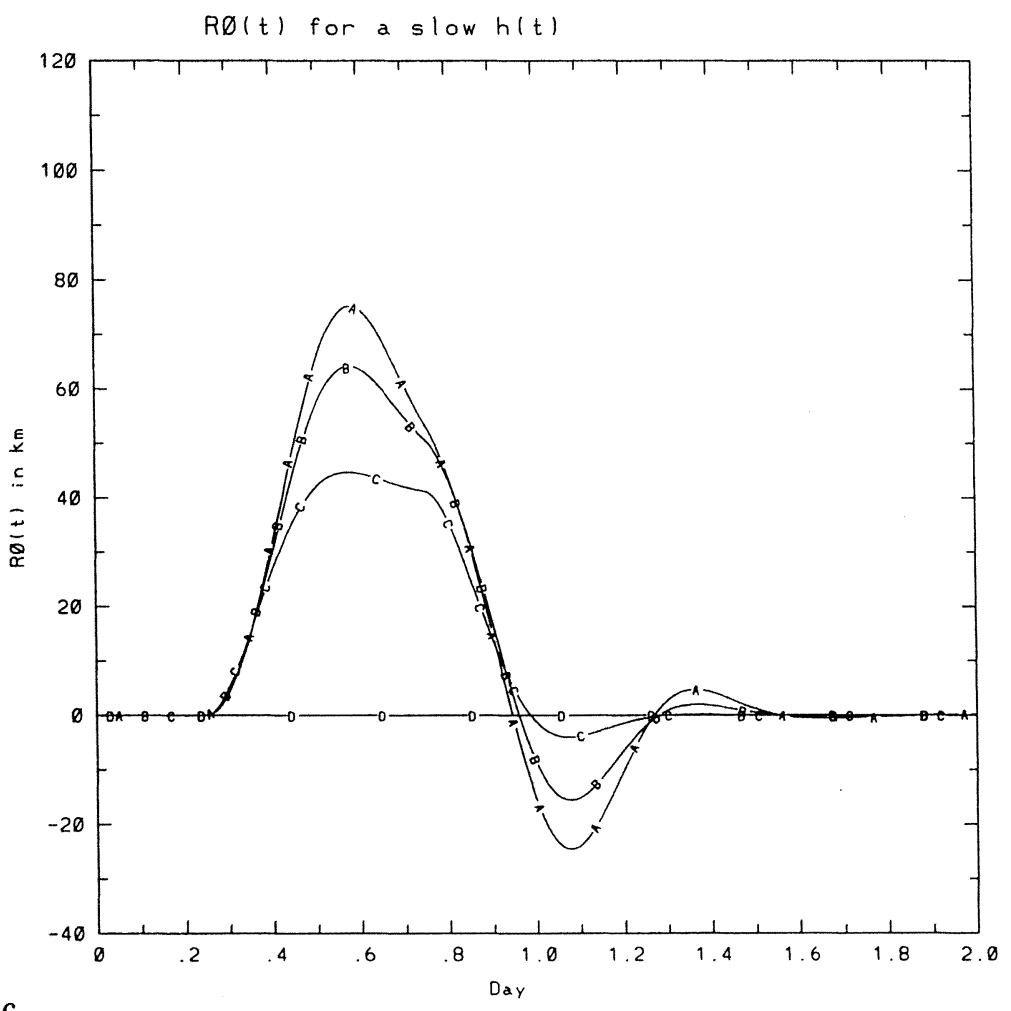

Figure 2. Continued.

where:

$$
\begin{aligned}
& a=f^{2}-\Omega^{2}+D^{2} \quad b=N^{2}-\Omega^{2}+D^{2} \\
& c=2 D \Omega \quad d=c\left[\frac{\mu_{0}^{2}-k_{0}^{2}}{a \mu_{0}^{2}-b k_{0}^{2}}\right] .
\end{aligned}
$$

\subsection{DISSIPATIVE THERMODYNAMIC IMPRINT}

To evaluate the net thermodynamic imprint due to the irreversible processes on the free atmosphere we adopt a periodic forcing, with a net diabatic input averaged to zero in a day. In a time cycle, each air particle describes a trajectory which is a closed elongated ellipses, Figure 3 . The ratio between the minor and the major axis of the ellipses increases as the dissipation increases: the major axis becomes smaller as the minor axis becomes larger. Since the trajectories are 


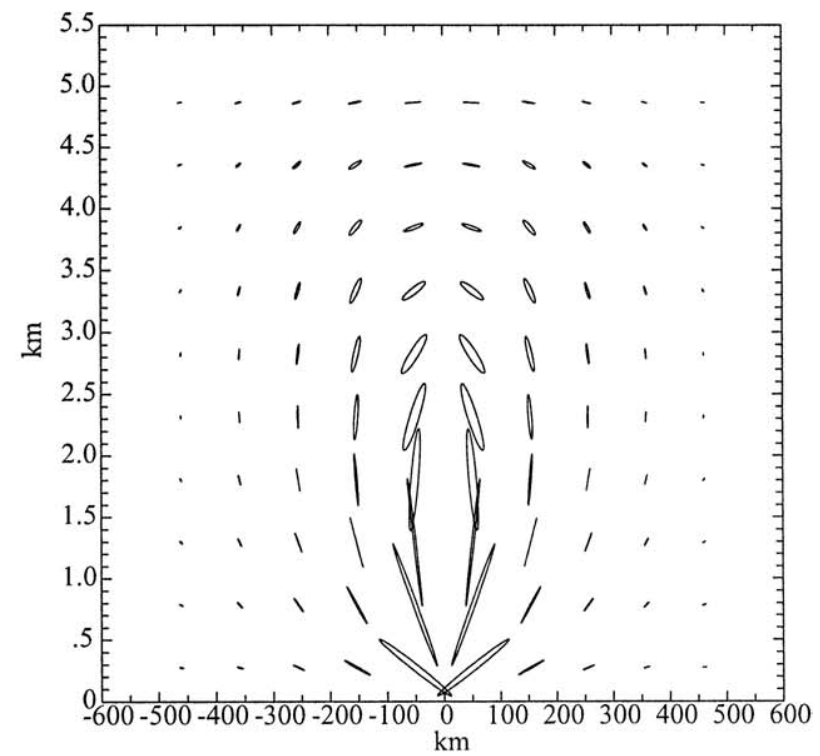

a.

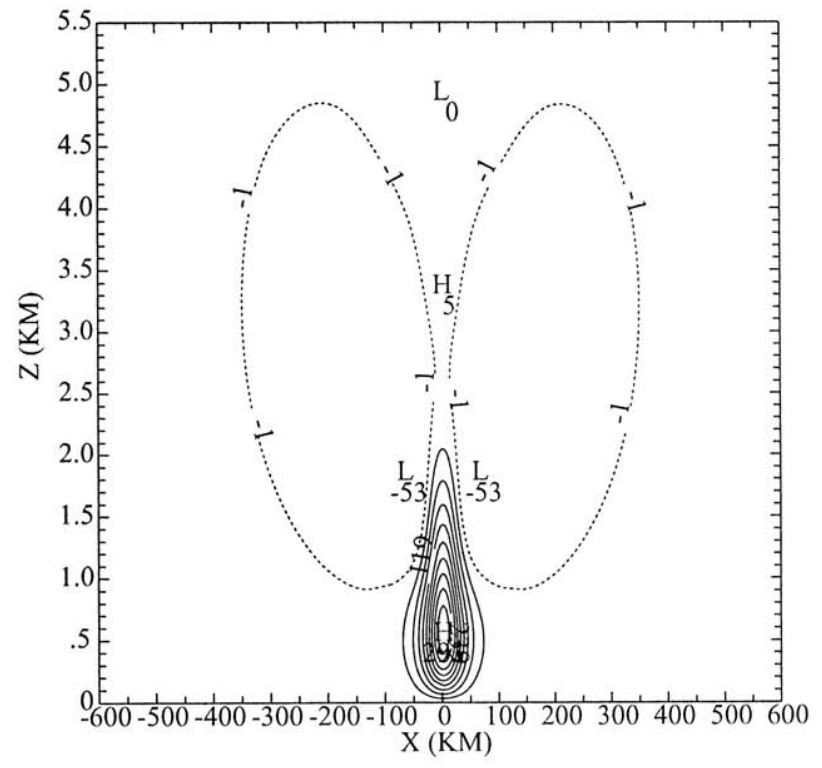

b.

Figure 3. Elliptical air particles trajectory under a periodic in time forcing, left panels; and thermodynamic imprint right panels. Friction and diffusion are larger in lower panels than in the upper panels. 


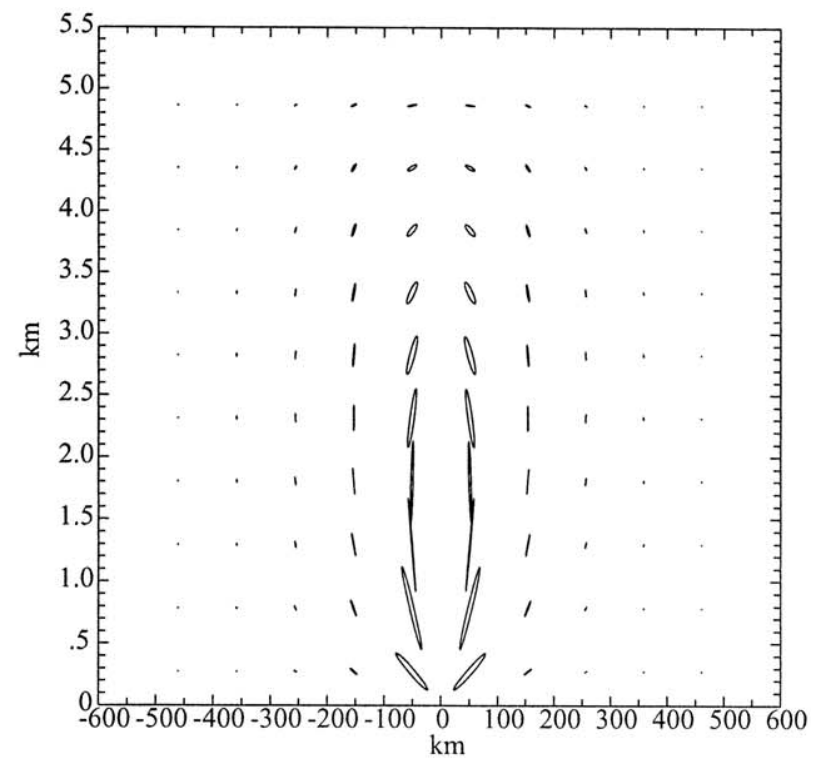

c.

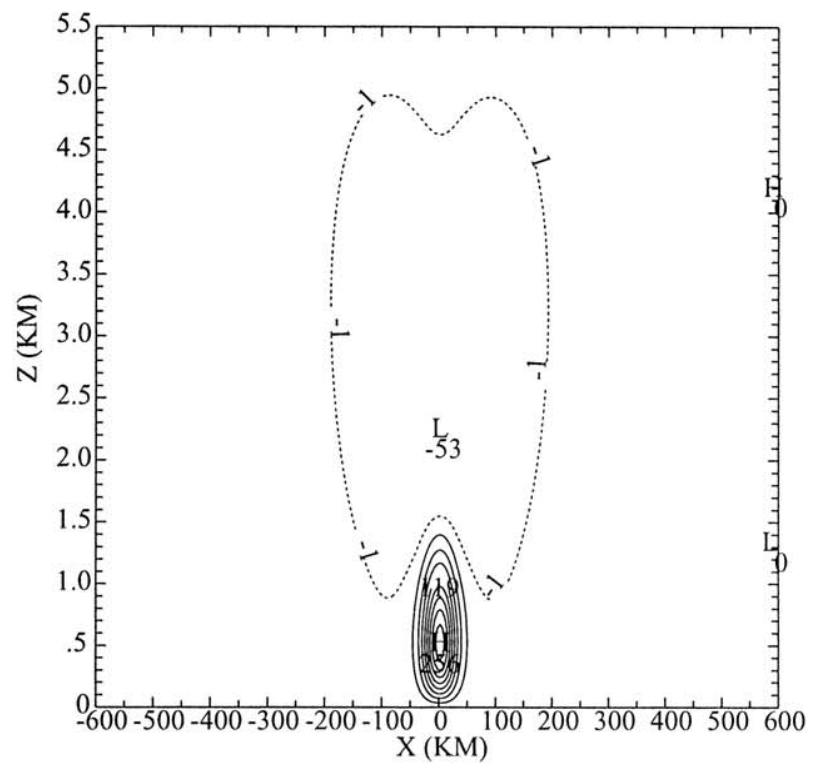

d.

Figure 3. Continued. 
closed, the net advected heat averages to zero. However, as the air particles describe their elliptical trajectories, they diffuse and partially mix in the environment. Each air particle interacts with the neighboring particles. The interaction distance is $r=\sqrt{K /\left(\lambda^{2}+\omega^{2}\right)^{\frac{1}{2}}}$, and the time scale is $\tau=1 / \sqrt{\left(\lambda^{2}+\omega^{2}\right)}$. The dissipative-diffusive process leaves a thermodynamic imprint with a nonzero average, as shown in Figure 3. This imprint is on the order of tenths of degrees, and may be of climatological significance, when integrated over all the coastal regions of the Earth (Walsh 1974). The temperature perturbation averaged over a cycle is:

$$
\begin{gathered}
\overline{\delta \theta^{\prime}(x, z)}=-\frac{\Theta_{z}}{2} \mathcal{F}^{-1}\left\{\tilde{a}_{1}\left[\left(\tilde{w}_{1}+\tilde{u}_{1}\right) \frac{\partial \tilde{\zeta}_{1}}{\partial x}+\left(\tilde{w}_{2}+\tilde{u}_{2}\right) \frac{\partial \tilde{\zeta}_{2}}{\partial x}\right]\right. \\
\left.-\tilde{a}_{2}\left[\left(\tilde{w}_{2}+\tilde{u}_{2}\right) \frac{\partial \tilde{\zeta}_{1}}{\partial z}-\left(\tilde{w}_{1}+\tilde{u}_{1}\right) \frac{\partial \tilde{\zeta}_{2}}{\partial x}\right]\right\} \\
\tilde{a}_{1}+j \tilde{a}_{2}=\frac{\left[\lambda+K\left(k^{2}+\mu^{2}\right)\right]-j \omega}{\left[\lambda+K\left(k^{2}+\mu^{2}\right)\right]^{2}+\omega^{2}} \approx \frac{\lambda-j \omega}{\lambda^{2}+\omega^{2}} \\
\text { when } \lambda \gg K\left(k^{2}+\mu^{2}\right) .
\end{gathered}
$$

When the dissipation and diffusion are negligible the net thermodynamic imprint is also negligible. The imprint increases with dissipation and diffusion; however, for very large values of dissipation, it decreases since the intensity of the flow decreases and the dimensions of the ellipses described by the air particles collapse.

\subsection{HEAT AND MOMENTUM FLUXES}

The rate at which the temperature is perturbed and the temperature perturbation, $\delta \theta$, due to the displacement of the air particles, $\xi$ and $\zeta$, are, respectively

$$
-\left(u^{L_{N H}} \partial_{x} \Theta+w^{L_{N H}} \partial_{z} \Theta\right) ; \quad \text { and } \quad \delta \theta=-\left[\xi \partial_{x} \Theta+\zeta \partial_{z} \Theta\right] .
$$

The horizontally averaged vertical heat flux is defined as $\langle w \theta\rangle$, where $w$ is the vertical velocity and $\theta$ is the temperature perturbation. The vertical fluxes are averaged over a horizontal domain equal to twice the Rossby radius, $2 R_{0}$ :

$$
<w \theta>=\frac{1}{2 R_{0}} \int_{-R_{0}}^{R_{0}}(w \theta) d x
$$

Figure 4 shows the vertical flux of temperature and heat rate for different size of the patches relative to the Rossby radius, for different values of the large scale flow $U$ and in presence and absence of diffusion $K$. The diabatic heat flux, $\langle\Phi\rangle$, averaged over a horizontal extent of two Rossby radius is shown in Figures 4a1,b1,c1. 


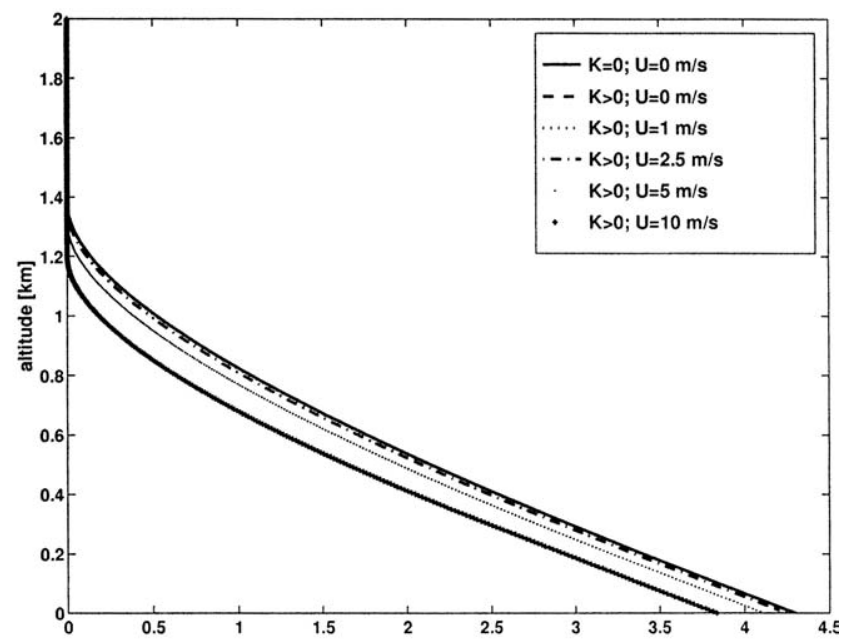

a1. Diabatic flux $\langle\Phi\rangle[\mathrm{K} \mathrm{km} /$ day $]$

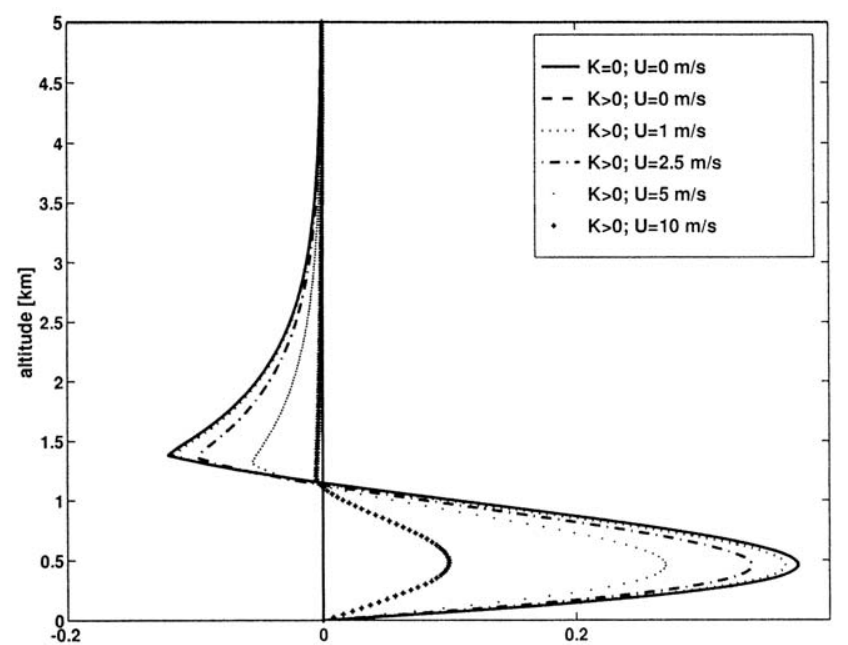

a2. Heat flux $\langle w \theta\rangle[\mathrm{K} \mathrm{km} /$ day $]$

Figure 4. Diabatic heat flux in kelvin degree kilometer per day, $\langle\Phi\rangle$, and vertical mesoscale heat flux, $\langle w \theta\rangle$, as a function of the horizontal wavenumber $k$, for different values of the large scale flow $U$, in the absence of diffusion, $K=0$, and in the presence of diffusion $K=$ $100 \mathrm{~m}^{2} / \mathrm{s}$ a1 and a2: $k=10^{-2}\left[\mathrm{~km}^{-1}\right]$; b1 and b2: $k=3 \cdot 10^{-2}\left[\mathrm{~km}^{-1}\right] ; \mathrm{c} 1$ and $\mathrm{c} 2: k=6$. $10^{-2}\left[\mathrm{~km}^{-1}\right]$. 


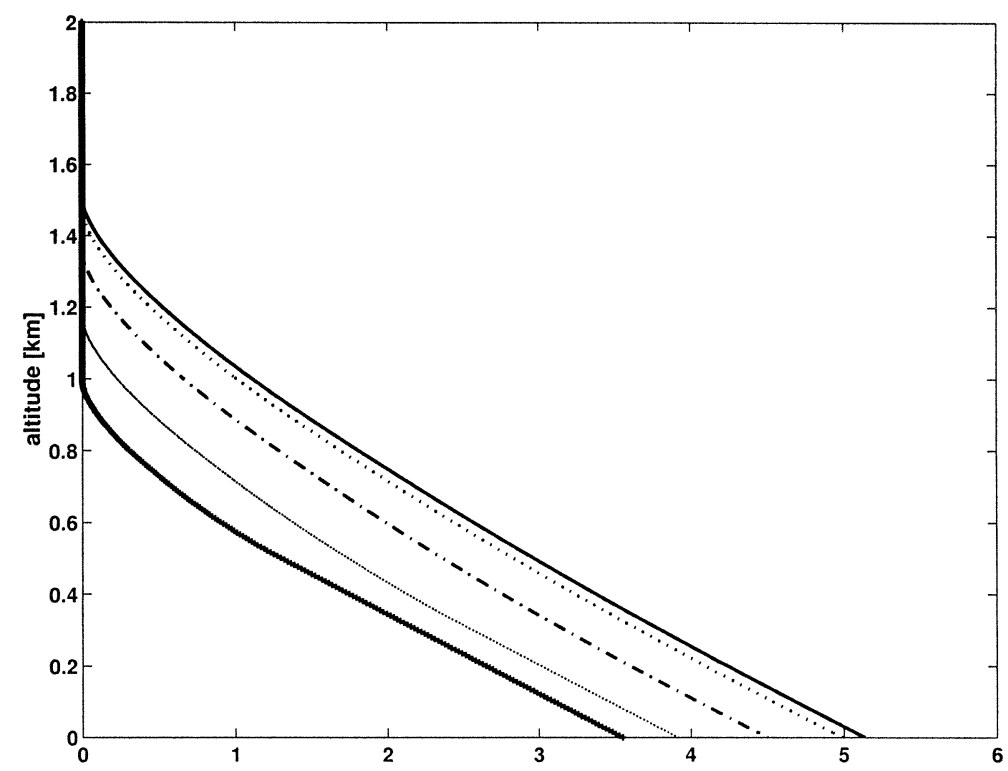

b1. Diabatic flux $\langle\Phi\rangle[\mathrm{K} \mathrm{km} /$ day $]$

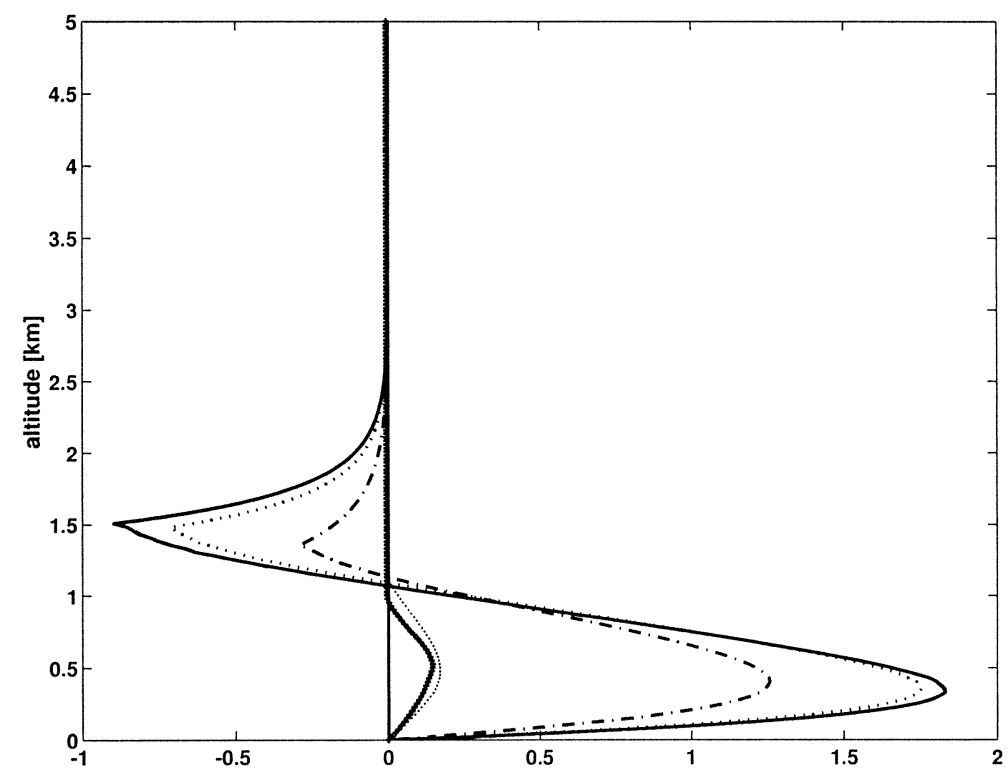

b2. Heat flux $\langle w \theta\rangle[\mathrm{K} \mathrm{km} /$ day]

Figure 4. Continued. 


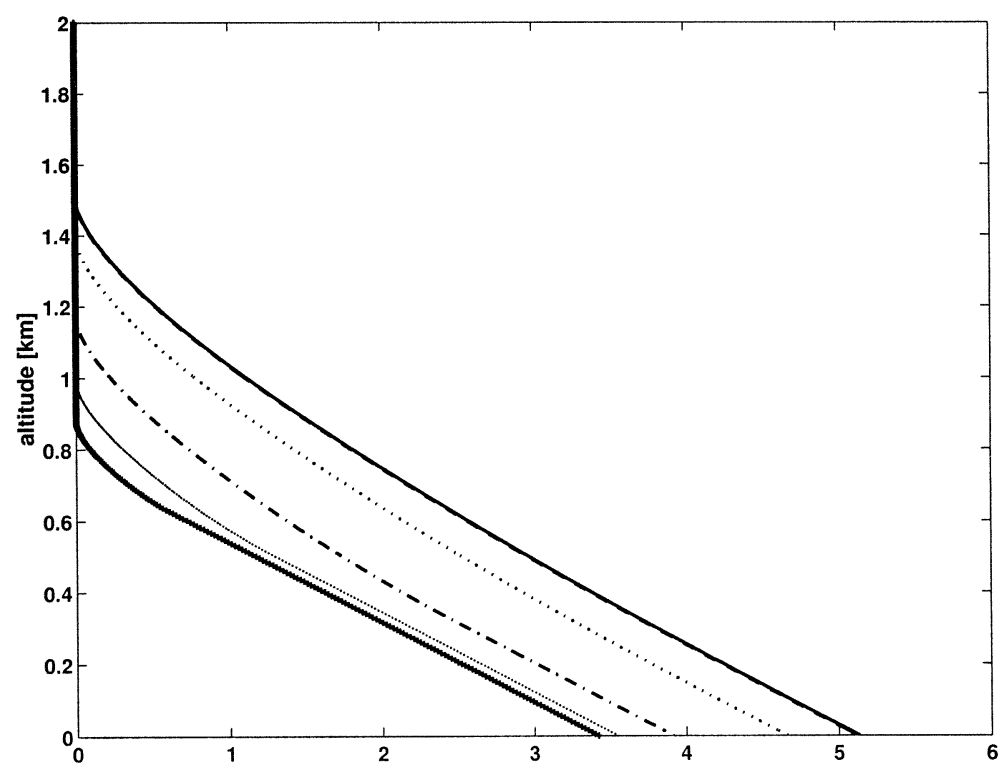

c1. Diabatic flux $\langle\Phi\rangle[\mathrm{K} \mathrm{km} /$ day $]$

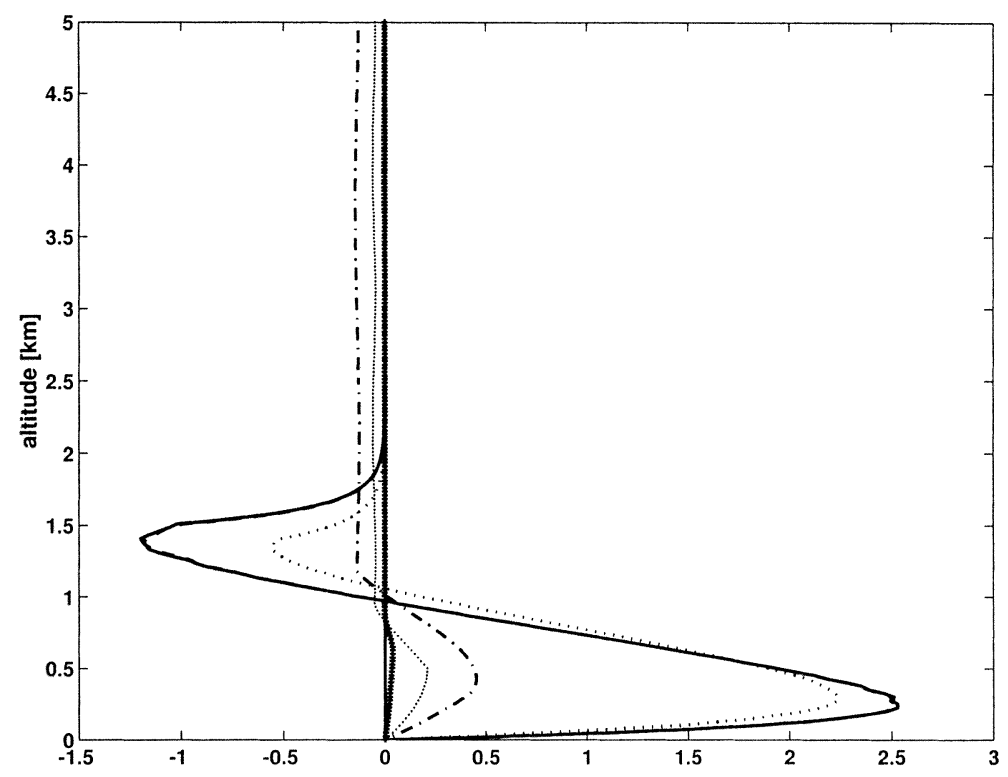

c2. Heat flux $\langle w \theta\rangle[\mathrm{K} \mathrm{km} /$ day $]$

Figure 4. Continued. 
$<\Phi>$ is vertically confined within the average depth of the CBL. Within the same frame, different curves refer to different values of the large scale flow and of the dissipation. Each frame refers to a different horizontal wavenumber. The diabatic heat flux $\langle\Phi\rangle$ is weakly sensitive over a range of values of the dissipation, $K=0-100 \mathrm{~m}^{2} / \mathrm{s}$, of the large scale flow intensity, $U=0-10 \mathrm{~m} / \mathrm{s}$, and wavenumber $k=1-6 \times 10^{-2} \mathrm{~km}^{-1}$. The sensitivity increases as the wavenumber increases, however, the intensity and the vertical penetration of $\langle\Phi>$ remain of the same order, except at high wavenumber when the large scale flow is intense.

The behavior of the induced mesoscale heat flux $<w \theta>$ is more complex than that of $\langle\Phi\rangle$. In the absence of synoptic flow, or when the synoptic flow is weak, the mesoscale flow is trapped $\left(\mu_{1}^{2}>0\right)$, see Figures $4 \mathrm{a} 2, \mathrm{~b} 2, \mathrm{c} 2 .<w \theta>$ is zero at the ground, positive within the CBL, and it is negative in the free atmosphere above, through a depth of the same order as $<\Phi>$; e.g., the mesoscale diabatically forced flow influences the atmosphere through a depth of about twice the depth of the CBL.

However, at very low wavenumbers, $\langle w \theta>$ is weaker than $\langle\Phi\rangle,\langle w \theta\rangle$ is only about one tenth of $\langle\Phi>$ when the large scale flow is weak, and it becomes even a smaller fraction as the intensity of the large scale flow increases (compare Figure $4 \mathrm{a} 1$ with Figure 4a2). When the wavelength is a sizeable fraction of the Rossby radius and the large scale flow is weak, the mesoscale systems are well developed, and $\langle w \theta>$, and $\langle\Phi\rangle$ are of the same order within the CBL. Mesoscale flows induced by forcing of wavenumber $k=2 \pi / R o$ (Figure 4b2) and of wavenumber $k=2 \pi / R o$ (Figure $4 \mathrm{c} 2$ ) are more robust to the large-scale flow.

Figure 5 shows the vertical flux of temperature and momentum over an isolated patch. The panels ( $a$ and $c$ ) show the vertical velocity isolines and horizontally averaged heat rate in the absence of synoptic flow, over an isolated heat source. The momentum injected upstream is removed downstream and the horizontal average of momentum flux is zero. The following two panels $(b, d)$ show a vertical profile of horizontally averaged heat rate in the presence of synoptic flow of $2.5 \mathrm{~m} \mathrm{~s}^{-1}$. The last panel (e) show vertical profile of mometum flux in the presence of synoptic flow of $2.5 \mathrm{~m} \mathrm{~s}^{-1}$.

\section{The Linear Non-hydrostatic Geopotential Equation}

To derive the linear geopotential, we differentiate the 1 st momentum equation by $x$ and multiply by $\mathcal{L}$, add the 2nd momentum equation differentiated by $x$ and multiplied by $f$; add the 3rd momentum equation differentiated by $z$ and multiplied by $\mathcal{L}$, then add the buoyancy equation differentiated by $z$ yielding

$$
\mathcal{L} \nabla^{2} \phi^{L}=\frac{\partial Q}{\partial z}-\frac{\partial}{\partial z}\left[u^{L} \frac{\partial B}{\partial x}+w^{L} \frac{\partial B}{\partial z}\right]-\left[f^{2} \frac{\partial u^{L}}{\partial x}+N^{2} \frac{\partial w^{L}}{\partial z}\right]
$$



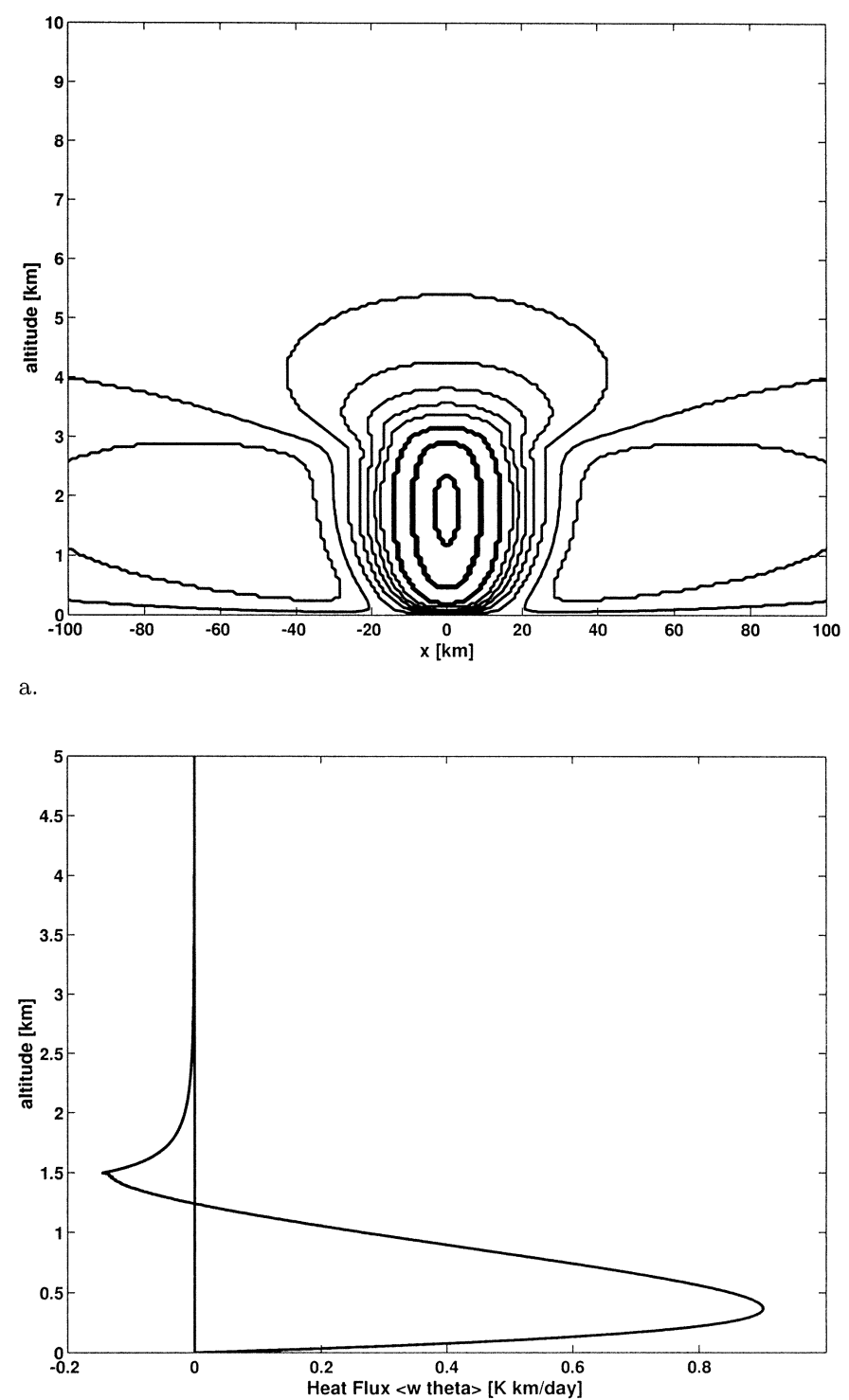

b.

Figure 5. Figure 5 shows the vertical flux of temperature and momentum over an isolated patch. The panels (a and c) show the vertical velocity isolines and horizontally averaged heat rate in the absence of synoptic flow, over an isolated heat source. The momentum injected upstream is removed downstream and the horizontal average of momentum flux is zero. The following two panels $(b, d)$ show a vertical profile of the horizontally averaged heat rate in the presence of synoptic flow of $2.5 \mathrm{~m} \mathrm{~s}^{-1}$. The last panel (e) show vertical profile of mometum flux in the presence of synoptic flow of $2.5 \mathrm{~m} \mathrm{~s}^{-1}$. 


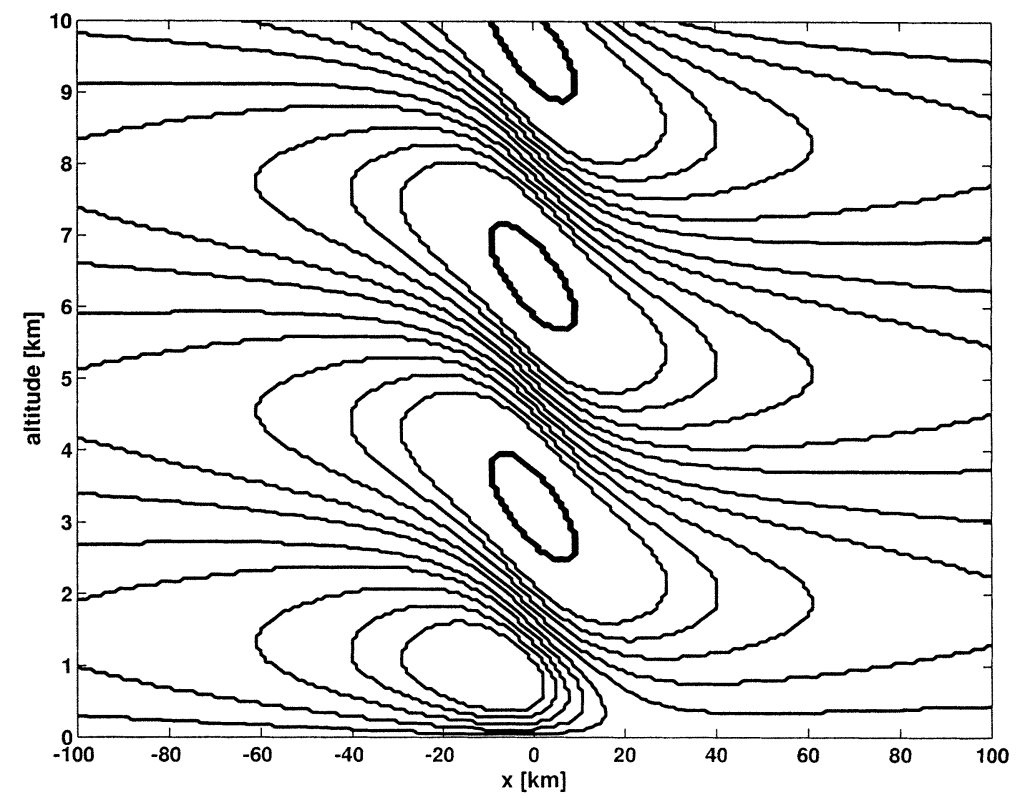

c.

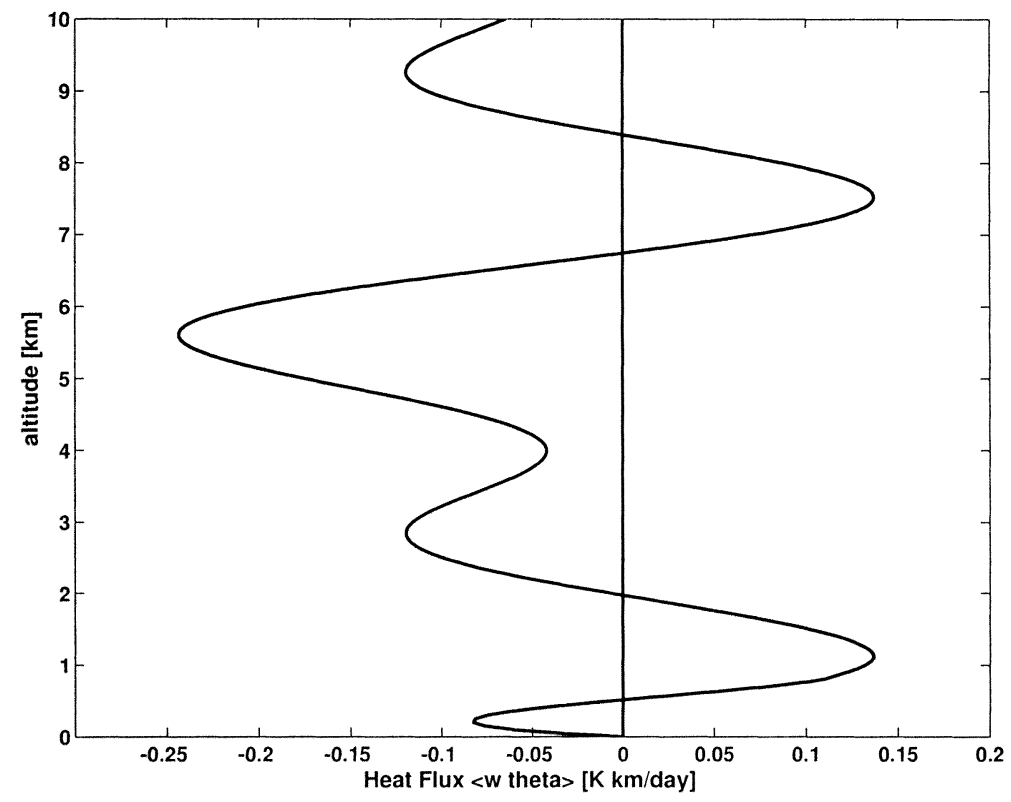

d.

Figure 5. Continued. 


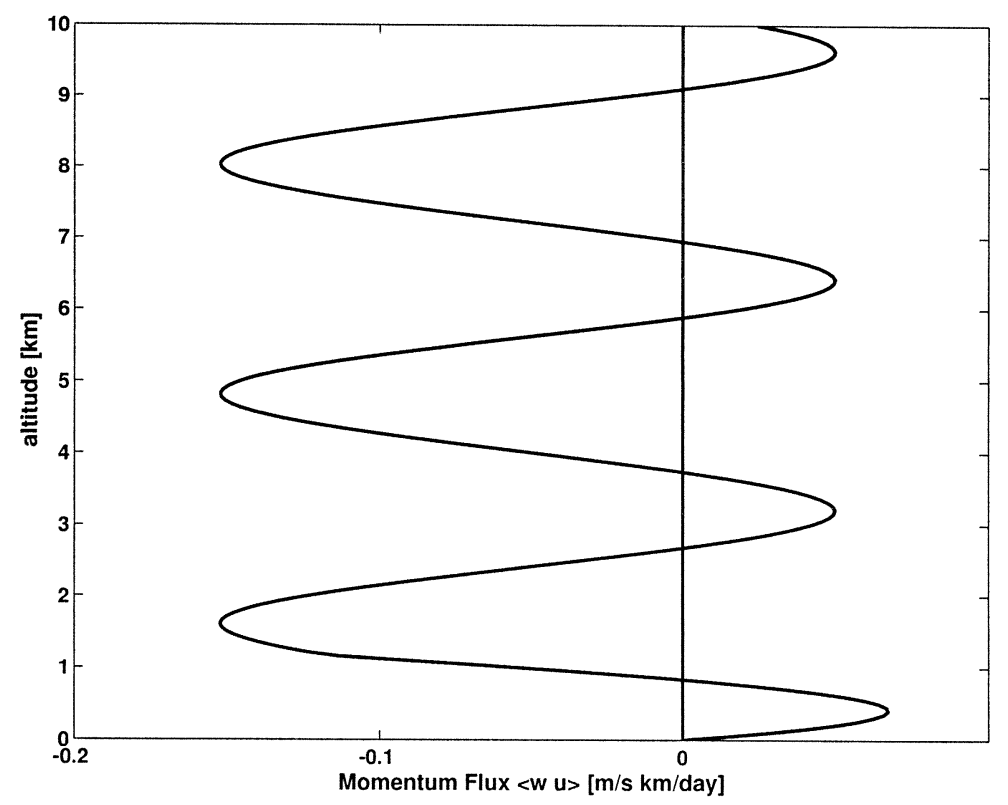

e.

Figure 5. Continued.

which, using continuity, becomes:

$$
\begin{gathered}
\mathcal{L} \nabla^{2} \phi^{L_{N H}}=\left[\partial_{z} Q-\partial_{z}\left(u^{L_{N H}} \partial_{x} B+w^{L_{N H}} \partial_{z} B\right)\right. \\
\left.+\left(N^{2}-f^{2}\right) \partial_{x} u^{L_{N H}}\right] \\
\nabla^{2} \phi^{L_{N H}}=\nabla^{2} \phi_{Q}+\nabla^{2} \phi_{B}^{L_{N H}}+\nabla^{2} \phi_{D}^{L_{N H}} .
\end{gathered}
$$

The three terms in the last equation are linear components to the geopotential $\phi^{L}$ :

$$
\begin{aligned}
& \mathcal{L} \nabla^{2} \phi_{Q}=\partial_{z} Q \\
& \mathcal{L} \nabla^{2} \phi_{B}^{L}=-\partial_{z}\left(u^{L} \partial_{x} B+w^{L} \partial_{z} B\right) \quad B=\mathcal{F}^{-1}\left\{\tilde{\mathcal{L}^{-1}} \tilde{Q}\right\} \\
& \mathcal{L} \nabla^{2} \phi_{D}^{L}=\left(N^{2}-f^{2}\right) \partial_{x} u^{L} .
\end{aligned}
$$




\section{Nonlinear Formulation}

The linear operator $\mathcal{L}$, needs to be replaced by the nonlinear operator $\mathcal{N} \mathscr{L}$ in the dynamical equations:

$$
\begin{array}{r}
\mathcal{N} \mathcal{L} \equiv \partial_{t}+u \partial_{x}+w \partial_{z}+\lambda-K \\
\nabla^{2}=\mathcal{L}+u \partial_{x}+w \partial_{z} .
\end{array}
$$

The nonlinear and hydrostatic form of the equations are:

$$
\begin{aligned}
\mathcal{N} \mathcal{L} u^{N L}-f v^{N L}+\phi_{x}^{N L} & =0 \\
\mathcal{N} \mathcal{L} v^{N L}+f u^{N L} & =0 \\
\phi_{z}^{N L} & =b^{N L} \\
\mathcal{N} \mathcal{L} b^{N L}+N^{2} w^{N L} B_{x} u^{N L}+B_{z} w^{N L} & =Q ; \\
u_{x}^{N L}+w_{z}^{N L} & =0 .
\end{aligned}
$$

The nonlinear and non-hydrostatic form of the equations are:

$$
\begin{aligned}
\mathcal{N} \mathcal{L} u^{N L}-f v^{N L}+\phi_{x}^{N L} & =0 \\
\mathcal{N} \mathcal{L} v^{N L}+f u^{N L} & =0 \\
\mathcal{N} \mathcal{L} w^{N L}+\phi_{z}^{N L} & =b^{N L} \\
\mathcal{N} \mathcal{L} b^{N L}+N^{2} w^{N L} B_{x} u^{N L}+B_{z} w^{N L} & =Q ; \\
u_{x}^{N L}+w_{z}^{N L} & =0 .
\end{aligned}
$$

The term $B_{x} u^{N L}+B_{z} w^{N L}$ is the dynamical deformation induced by the advection on the diabatic buoyancy perturbation $B$.

\section{The Nonlinear Geopotential}

To derive the nonlinear geopotential, we differentiate by $x$ the 1 st momentum equation, by $z$ the 3 rd momentum equation and add to obtain:

$$
\nabla^{2} \phi^{N L}=\frac{\partial b^{N L}}{\partial z}-\left[\frac{\partial^{2}\left(u^{N L}\right)^{2}}{\partial x^{2}}+2 \frac{\partial^{2}\left(w^{N L} u^{N L}\right)}{\partial x \partial z}+\frac{\partial^{2}\left(w^{N L}\right)^{2}}{\partial z^{2}}\right]+f \frac{\partial v^{N L}}{\partial x} .
$$

The equations for the nonlinear contribution to the geopotential is then:

$$
\begin{array}{r}
\mathcal{L} \nabla^{2}\left(\phi^{N L}-\phi^{L}\right)=\mathcal{L} \nabla^{2} \delta \phi^{N L} \approx \\
\approx \partial_{z}\left[u^{L} \partial_{x} \Delta B+w^{L} \partial_{z} \Delta B\right]-\mathcal{L}\left[\left(\partial_{x} u^{L}\right)^{2}+2\left(\partial_{x} w^{L} \partial_{z} u^{L}\right)+\left(\partial_{z} w^{L}\right)^{2}\right] .
\end{array}
$$



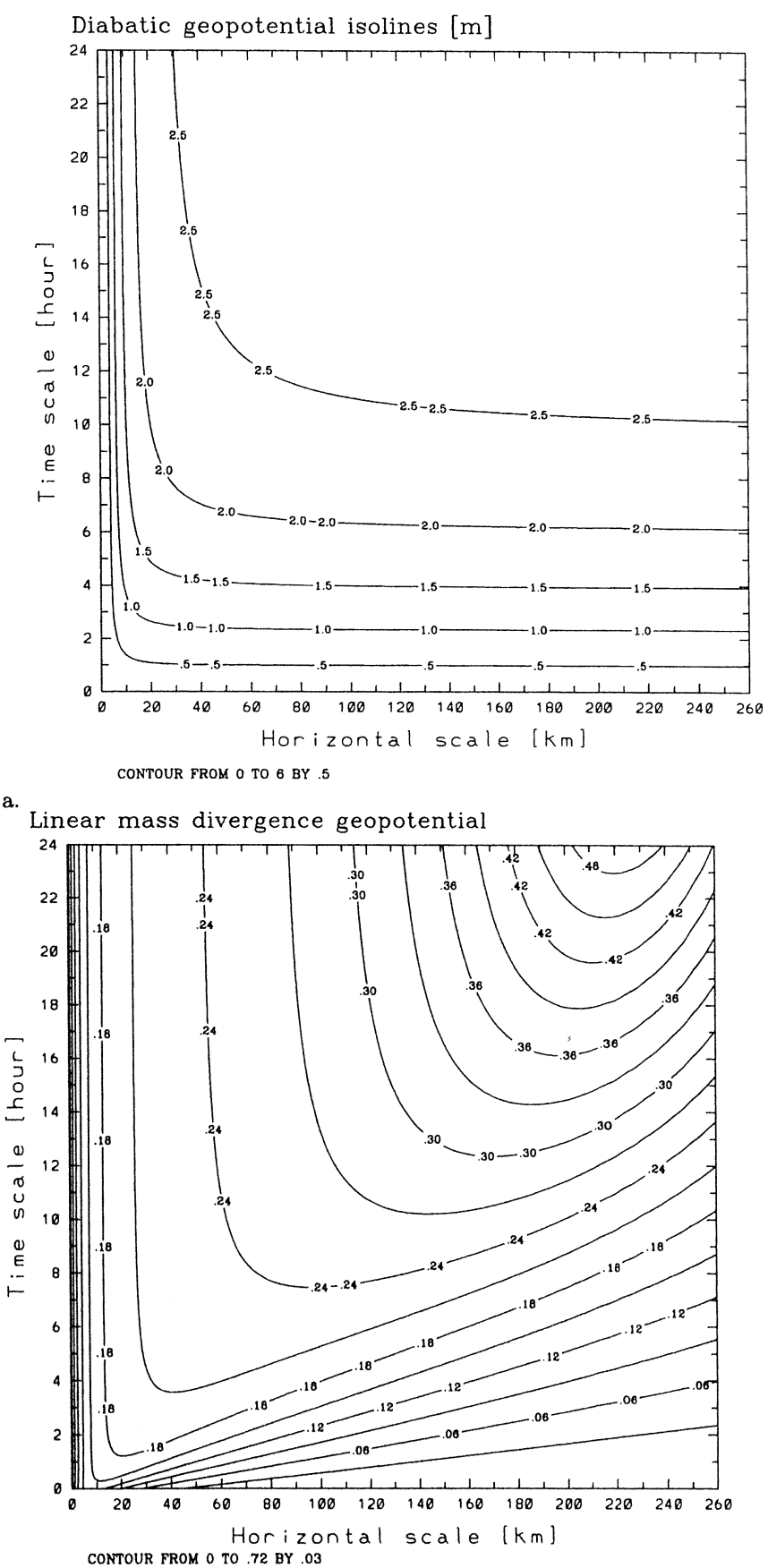

b.

Figure 6. Geopotentials as a function of time-space. $\mathcal{L} \phi_{Q}=\partial_{z} Q$ in meters, while $\mathcal{L} \nabla^{2} \phi_{D}{ }^{L}$ $=\left(N^{2}-f^{2}\right) \partial_{x} u^{L}, \mathcal{L} \nabla^{2} \phi_{B}{ }^{L}=-\partial_{z}\left(u^{L} \partial_{x} B+w^{L} \partial_{z} B\right), \delta \phi^{N L}=\phi^{N L}-\phi^{N L}$, are normalized by $\phi_{Q}$. The PBL forcing is periodic in time-space and exponentially decaying vertically. 


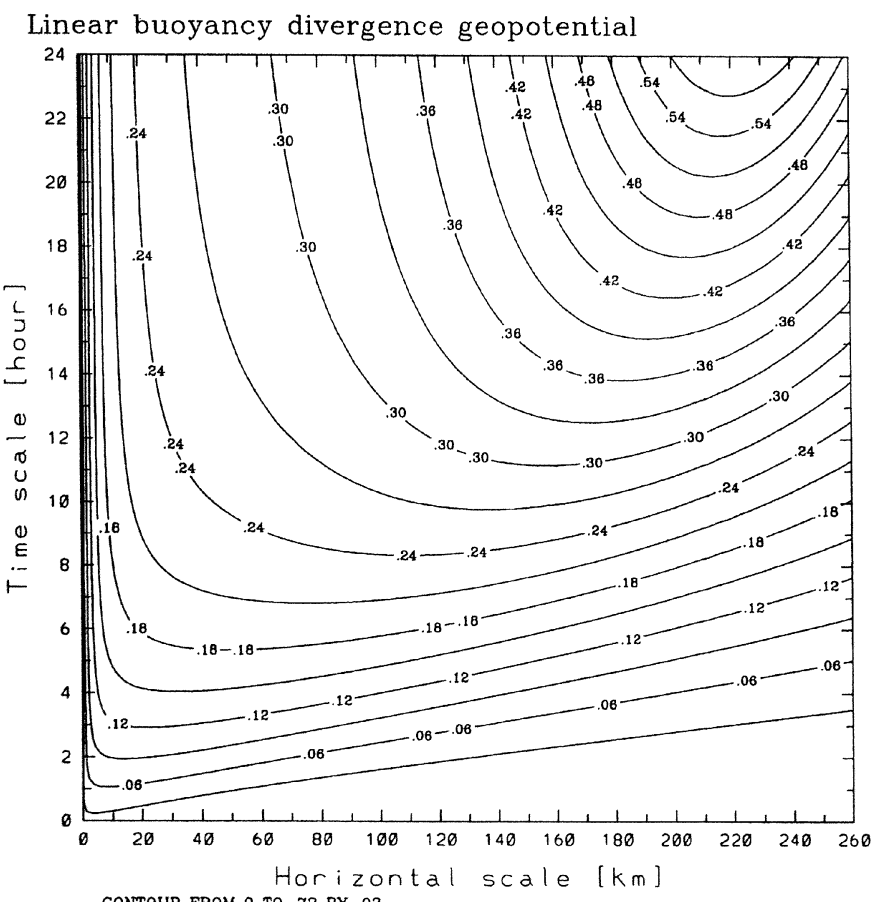

c. Nonlinear geopotential

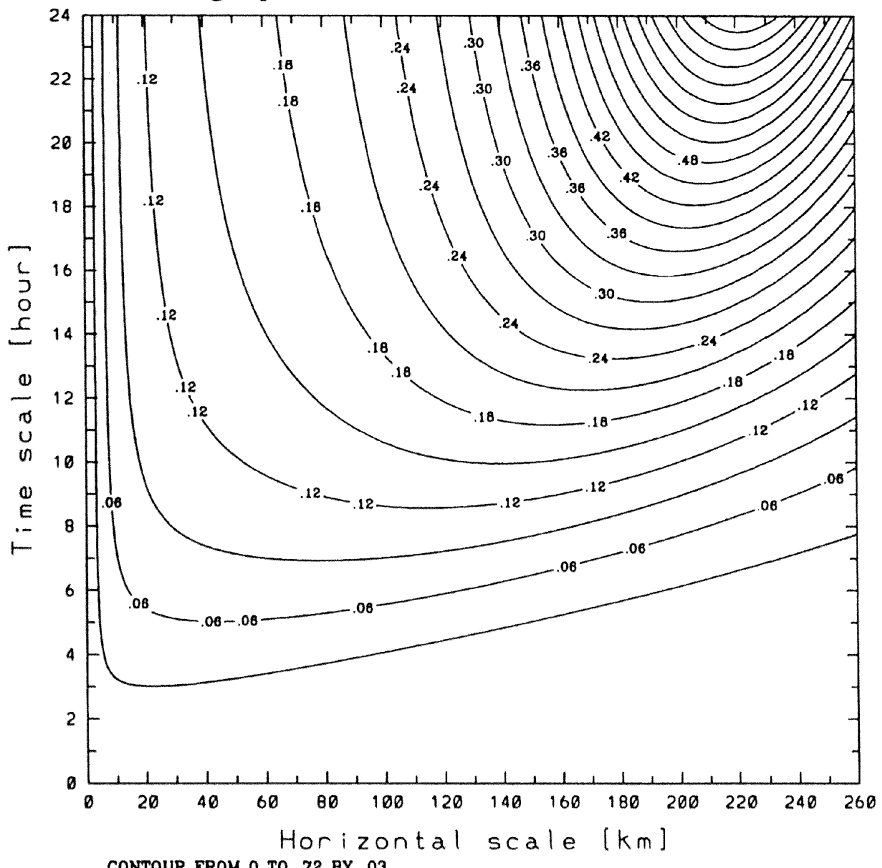

d. CONTOUR FROM O TO 72 BY 03

Figure 6. Continued. 
Some of the results are derived through linear theory, the nonlinear contribution is recovered using perturbation (expansion) theory.

Figure 6 shows the geopotential as a function of time-space. $\mathcal{L} \phi_{Q}=\partial_{z} Q$ in meters, while $\mathcal{L} \nabla^{2} \phi_{D}{ }^{L}=\left(N^{2}-f^{2}\right) \partial_{x} u^{L}, \mathcal{L} \nabla^{2} \phi_{B}{ }^{L}=-\partial_{z}\left(u^{L} \partial_{x} B+w^{L} \partial_{z} B\right)$, $\delta \phi^{N L}=\phi^{N L}-\phi^{N L}$, are normalized by $\phi_{Q}$. The PBL forcing is periodic in time-space and exponentially decaying vertically. We show the geopotential $\phi_{Q}$, and the isobaric anomaly in meters as directly deformed by the heat source. The other geopotentials are normalized by $\phi_{Q}$. The geopotential $\phi_{D}$ results from the convergence-divergence of mass, and is always a relevant term in ageostrophic geophysical mesoscale stratified flows. $\phi_{D}$ is an important fraction of $\phi_{Q}$. Since $\phi_{D} \propto\left(N^{2}-f^{2}\right) k_{0} u^{N H}$, this geopotential becomes generally small when the atmosphere is non-stratified $N^{2} \approx 0$, with only a contribution due to the remaining inertia force, which cannot be neglected in semi-geostrophic flows such as cold fronts, or in the regional lifting by convergence lines [63].

Since the mesoscale flow is mainly driven by the pressure gradient forces directly generated by the diabatic heat source, $\nabla \phi_{D}$, in order to weigh the relative importance of the pressure terms $\phi_{D}, \phi_{B}$ and $\delta \phi_{B}^{N L}$, in Figure 7 we show the region in time-space where $\phi_{D}, \phi_{B}$, and $\delta \phi_{B}^{N L}$ exceed $\phi_{Q}$ by $10 \%, 25 \%$, and $50 \%$. When a pressure term exceeds $10 \%$ of $\phi_{D}$, we assume the term cannot be neglected. When it exceeds the $25 \%$ threshold, it produces a clearly sizeable deformation of the pressure pattern and of the flow field. Finally, where the pressure terms exceed the 50\% threshold, it means that the mesoscale dynamics at the spatial scale have sufficient time to be fully developed.

The Regional Atmospheric Modelling System (RAMS) has been adopted in order to get the fully nonlinear results, and the study is still in progress.

\section{Conclusions}

Weak large scale ambient flows are favorable to the development of mesoscale flows driven by thermal inhomogeneities in the boundary layer. The horizontal scale of the flow grows through gravity-inertia oscillations, damped because of friction and diffusion. CBL mixing is on the order of few degrees, and works towards the weakening of the stability of the lower levels of the atmosphere. Mixing is an adiabatic and irreversible process, which leaves a permanent imprint, the thermodynamic perturbation associated with it is on the order of half a degree.

The mesoscale is capable of transporting diabatic heat upwards in competition with the subgrid turbulent flux. Large amounts of heat can be injected into the lower half of the troposphere through mesoscale processes, thereby changing the average large scale characteristics of the atmosphere, such as weakening of the average static stability.

In the absence of larger scale ambient flow, the vertical heat mesoscale flux is of the same order as the turbulent diabatic heat flux. 

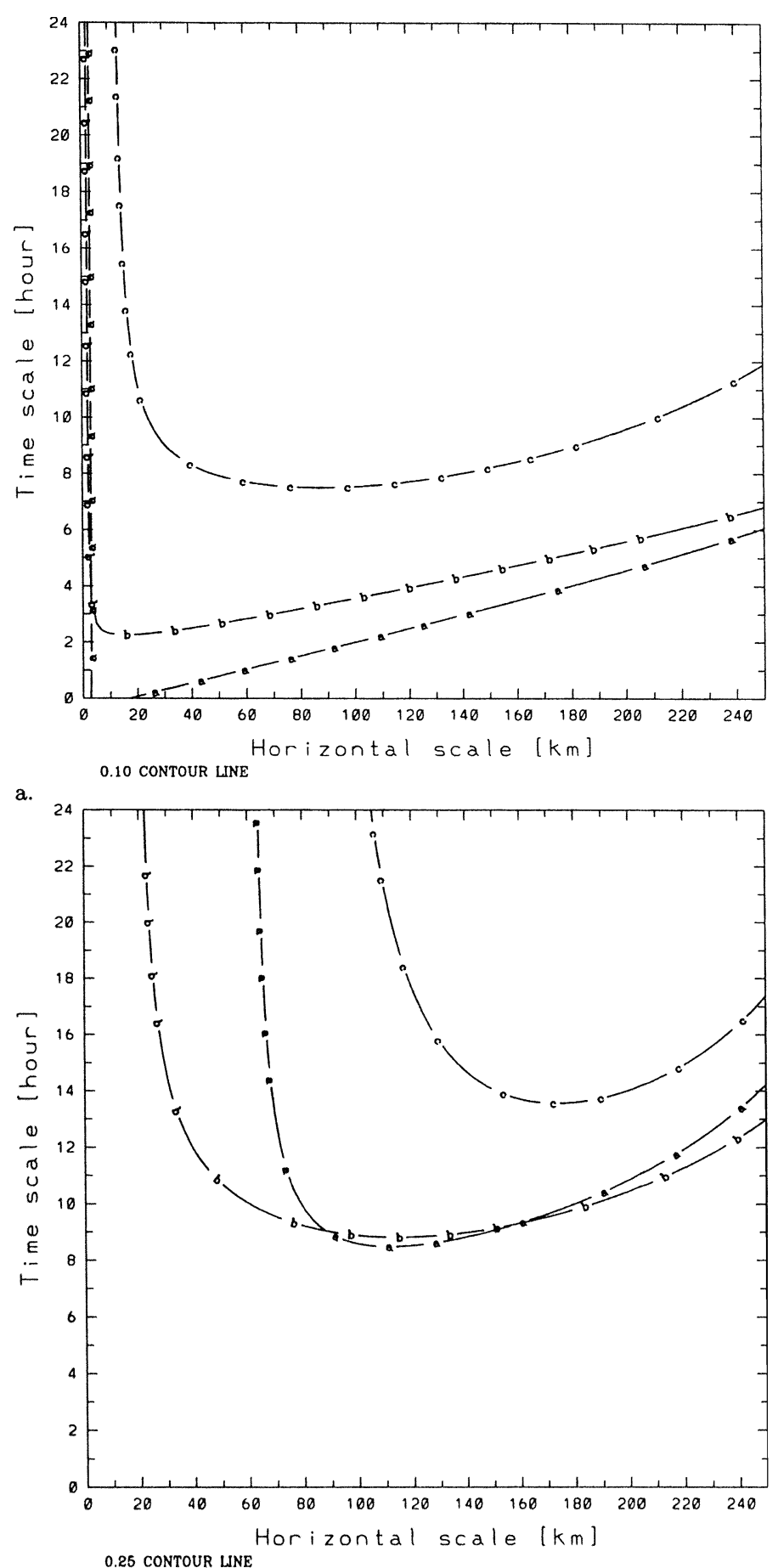

b.

Figure 7. Regions in time-space where $\phi_{D}, \phi_{B}$, and $\delta \phi_{B}^{N L}$ exceed $\phi_{Q}$ by $10 \%, 25 \%$, and $50 \%$. 


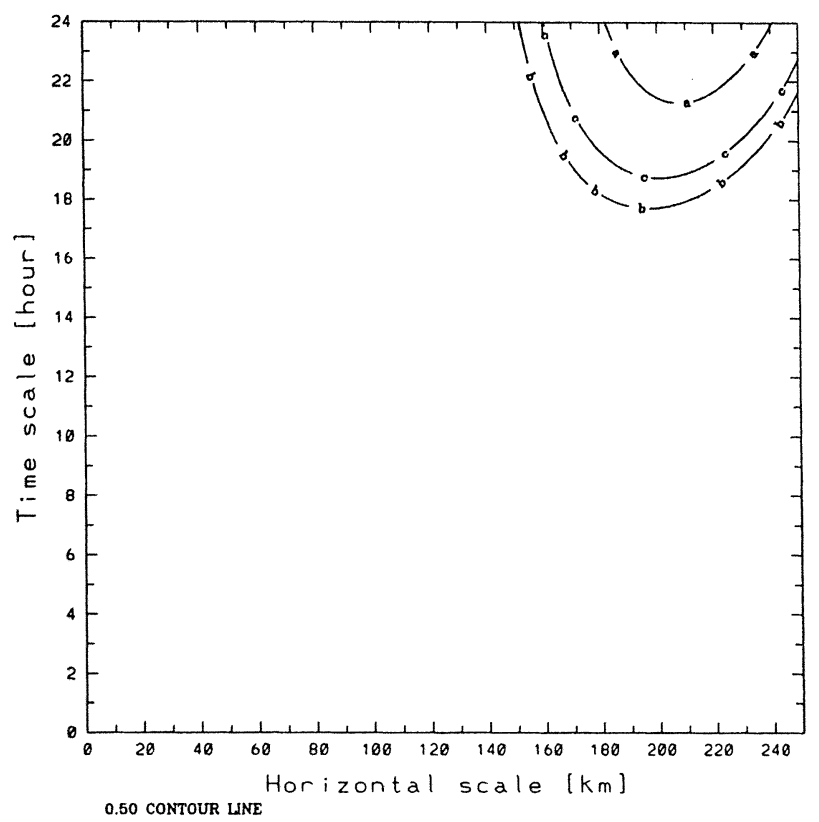

c.

Figure 7. Continued.

The mesoscale vertical fluxes into the free atmosphere, are negligible when the wavelength of the inhomogeneity is much larger than the Rossby radius because of low pressure forces; or when the wavelength of the inhomogeneity is smaller than the CBL depth, because of mixing.

The presence of a synoptic flow weakens the mesoscale flow intensity. However, when the large scale flow is not strong enough to obliterate the mesoscale flow, measurable wave activity is triggered by the thermal inhomogeneities. In this case, the entire troposphere is affected by momentum and heat fluxes associated with the mesoscale perturbation. The momentum fluxes are downward for this case, while in the free atmosphere the heat fluxes are negative, because of the mixing of the air particles displaced by the waves with the environment. As a result, the waves export momentum into the CBL, where it is dissipated by the turbulence.

When not resolved explicitly, the mesoscale heat fluxes can be introduced in large scale models in a parametric, or horizontally averaged form as applied in [1].

The mesoscale flow field is driven by the pressure gradient force generated by the diabatic source. Four additional pressure gradient terms are generated by the mesoscale dynamics: two terms are linear and two terms are nonlinear, these terms are generally non-hydrostatic. Depending on the space and time scales of the mesoscale system, these terms can be negligible, or contribute significantly to the mesoscale dynamics.

It is important to determine when the flow is predominantly hydrostatic. In this paper we have shown how, in a large range of time-space scales of the atmospheric 
flow, the hydrostatic approximation can be made. Most of the non-hydrostatic residual can be recovered using the correction that we suggest, which fails, however, when the aspect ratio is about one and the pulsation is comparable with the Brunt-Väisälä frequency; in this region the nonlinear dynamical pressure is also non-negligible.

The two linear pressure gradient terms associated with convergence-divergence of mass and with convergence-divergence of buoyancy are not usually negligible in atmospheric flows. The nonlinear pressure gradient term generated by the nonlinear advection of buoyancy cannot be neglected when the time scale of the flow is comparable to the inertial period. While the nonlinear dynamical pressure is relevant in the regions of rapidly changing gradients and pulsation rate.

In mesoscale flows, the pressure gradients are linear, except when the time scale is on the order of the Brunt-Väisälä period. In this case, the flow is also highly nonhydrostatic. When the time scale is on the order of the inertial period, the nonlinear advection of temperature becomes important, although the flow is hydrostatic.

When these perturbations and mesoscale effects are not resolved explicitly, as in large scale models, then they have to be introduced in the numerical models in a parametric form.

\section{Acknowledgements}

Support was provided by the National Science Foundation under Grant No. ATM9910857. G.A. Dalu and M. Baldi also acknowledge the support of the Italian Space Agency (MeditRain - ASI) and the Italian CNR Short-Term Mobility Program.

\section{References}

1. Avissar, R. and Pielke, R.A.: 1989, A parameterization of heterogeneous land surfaces for atmospheric numerical models and its impact on regional meteorology, Mon. Wea. Rev. 117, 2113-2136.

2. Chen, F. and Avissar, R.: 1994, Impact of land-surface moisture variabilities on local shallow convective cumulus and precipitation in large-scale models, J. Appl. Meteorol. 33, 1382-1394.

3. Cotton, W.R. and Pielke, R.A.: 1995, Human Impacts on Weather and Climate, Cambridge University Press, New York, p. 288.

4. Dalu, G.A. and Pielke, R.A.: 1989, An analytical study of the sea breeze, J. Atmos. Sci. 46, 1815-1825.

5. Ookouchi, Y., Segal, M., Kessler, R.C. and Pielke, R.A.: 1984, Evaluation of soil moisture effects on the generation and modification of mesoscale circulation, Mon. Wea. Rev. 117, 21132136.

6. Pielke Sr., R.A.: 2002, Mesoscale Meteorological Modeling, 2nd edition, Academic Press, San Diego, CA. 676 pp.

7. Rotunno, R.: 1983, On the linear theory of land and sea breeze, J. Atmos. Sci., 40, 1999-2009.

8. Segal, M., Avissar, R., McCumber, M.C. and Pielke, R.A.: 1988, Evaluation of vegetation effects on the generation and modification of mesoscale circulations, J. Atmos. Sci., 45, 22682292. 
9. Segal, M. and Arritt, R.W.: 1992, Non-classical mesoscale circulations caused by surface sensible heat-flux gradients, Bull. Amer. Meteorol. Soc. 73, 1593-1604.

10. Zhang, D. and Anthes, R.A.: 1982, A high-resolution model of the planetary boundary layersensitivity tests and comparisons with SESAME-79 data, J. Appl. Meteorol. 21, 1594-1609.

11. Garrett, A.J.: 1982, A parameter study of interactions between convective clouds, the convective boundary layer, and forested surface, Mon. Wea. Rev. 110, 1041-1059.

12. Yan, H. and Anthes, R.A.: 1988, The effect of variations in surface moisture on mesoscale circulations, Mon. Wea. Rev. 116, 192-208.

13. Dalu, G.A., Pielke, R.A., Vidale, P.L. and Baldi, M.: 2000, Heat transport and weakening of the atmospheric stability induced by mesoscale flows, J. Geophys. Res. 105, D7, 9349-9363.

14. Hanna, S.R. and Swisher, S.D.: 1971, Meteorological effects of the heat and moisture produced by man, Nucl. Saf. 12, 114-122.

15. Anthes, R.A.: 1984, Enhancement of convective precipitation by mesoscale variation in vegetative covering in semi-arid regions, J. Appl. Meteorol. 23, 541-554.

16. Segal, M., Pielke, R.A. and Mahrer, T.: 1984, Evaluation of surface sensible heat flux effects on the generation and modification of mesoscale circulations, In: Proc. Second Int. Symp. on Nowcasting, European Space Agency, Norrkoping, Sweden, pp. 263-269.

17. Segal, M., Schreiber, W., Kallos, G., Pielke, R.A., Garratt, J.R., Weaver, J., Rodi, A. and Wilson, J.: 1989, The impact of crop areas in northeast Colorado on midsummer mesoscale thermal circulations, Mon. Wea. Rev. 117, 809-825.

18. Abbs, D.J. and Pielke, R.A.: 1986, Thermally forced surface flow and convergence patterns over northeast Colorado. Mon. Wea. Rev. 114, 2281-2296.

19. Mahfouf, J-F., Richard, E. and Mascart, P.: 1987, The influence of soil and vegetation on the development of mesoscale circulations, J. Climate Appl. Meteorol. 26, 1483-1495.

20. Mahrer, Y. and Pielke, R.A.: 1977, A numerical study of the air flow over irregular terrain, Contrib. Atmos. Phys. 50, 98-113.

21. McCumber, M.C. and Pielke, R.A.: 1981, Simulation of the effects of surface fluxes of heat and moisture in a mesoscale numerical model, J. Geophys. Res. 86, 9929-9938.

22. Pielke R.A., Dalu, G.A., Snook, J.S., Lee, T.J. and Kittel, T.G.F.: 1991, Nonlinear influence of mesoscale land-use on weather and climate, J. Climate 4, 1053-1069.

23. Pielke, R.A., Rodriguez, J.H., Eastman, J.L., Walko, R.L. and Stocker, R.A.: 1993, Influence of albedo variability in complex terrain on mesoscale systems, J. Climate 6, 1798-1806.

24. Dalu, G.A., Pielke, R.A., Avissar, R., Kallos, G., Baldi, M. and Guerrini, A.: 1991, Linear impact of thermal inhomogeneities on mesoscale atmospheric flow with zero synoptic wind, Ann. Geophys. 9, 641-647.

25. Manqian, M. and Jinjun, J.: 1993, A coupled model on land-atmosphere interactions - simulating the characteristics of the PBL over a heterogeneous surface, Boundary-Layer Meteorol. 66, 247-264.

26. Raupach, M.R.: 1991, Vegetation-atmosphere interaction in homogeneous and heterogeneous terrain: Some implications of mixed layer dynamics. In: Henderson-Sellers and Pitman (eds.), Vegetation and Climate Interactions in Semi-Arid Regions, Dordrecht, The Netherlands, Kluwer Academic Publishers, pp. 105-120.

27. Guo, Y., and Schuepp, P.H.: 1994, An analysis of the effect of local heat advection on evaporation over wet and dry surface strips, J. Climate 7, 641-652.

28. Zhong, S. and Doran, J.C.: 1995, A modeling study of the effects of the effects of inhomogeneous surface fluxes on boundary-layer properties, J. Atmos. Sci. 52, 3129-3142.

29. Avissar, R. and Chen, F.: 1993, Development and analysis of prognostic equations for mesoscale kinetic energy and mesoscale (subgrid-scale) fluxes for large-scale atmospheric models, J. Atmos. Sci. 50, 3751-3774.

30. André, J.-C., Bougeault, P., Mahfouf, J.-F., Mascart, P., Noilhan, J. and Pinty, J.-P.: 1989, Impact of forests on mesoscale meteorology, Phil. Trans. Roy. Soc. London 324, 407-422. 
31. Zeng, X. and Pielke, R.A.: 1993, Error-growth dynamics and predictability of surface thermally-induced atmospheric flow, J. Atmos. Sci. 50, 2817-2844.

32. Zeng, X. and Pielke, R.A.: 1995, Further study on the predictability of landscape-induced atmospheric flow, J. Atmos. Sci. 52, 1680-1698.

33. Zeng, X.: 1992, Chaos theory and its application in the atmosphere, Atmospheric Science Paper No. 504, Colorado State University, R.A. Pielke, P.I., 178 pp.

34. Li, B. and Avissar, R.: 1994, The impact of spatial variability of land-surface heat fluxes, $J$. Climate 7, 527-537.

35. Kosta, R.D. and Suarez, M.J.: 1992, A comparative analysis of two land surface heterogeneity representations, J. Climate 5, 1379-1390.

36. Bonan, G.B., Pollard, D. and Thompson, S.L.: 1993, Influence of subgrid-scale heterogeneity in leaf area index, stomatal resistance, and soil moisture on grid-scale land-atmosphere interactions, J. Climate 6, 1882-1897.

37. Pleim, J.E. and Xiu, A.: 1995, Development and testing of a surface flux and planetary boundary layer model for application in mesoscale models, J. Appl. Meteorol. 34, 16-32.

38. Pitman, A.J. 1994, Assessing the sensitivity of a land-surface scheme to the parameter values using a single column model, J. Climate 7, 1856-1869.

39. Henderson-Sellers, A., Yang, Z.-L. and Dickinson, R.E.: 1993, The project for intercomparison of land-surface parameterization schemes, Bull. Amer. Meteorol. Soc. 74, 1335-1349.

40. Collins, D.C. and Avissar, R.: 1994, An evaluation with the Fourier Amplitude Sensitivity Test (FAST) of which land surface parameters are of greatest importance in atmospheric modeling, J. Climate 7, 681-703.

41. Arritt, R.W. and Clark, C.A.: 1994, Functional relationships among soil moisture, vegetation cover, and surface fluxes, In: Proc., Special Session on Hydrometeorology, AMS, March 7-10, 1994, San Diego, CA.

42. Glendening, J.W. and Lin, C.L.: 2002, Large eddy simulation of internal boundary layers created by a change in surface roughness, J. Atmos. Sci. 59, 1697-1711.

43. Lin, C.L. and Glendening, J.W.: 2002, Large eddy simulation of an inhomogeneous atmospheric boundary layer under neutral conditions, J. Atmos. Sci. 59, 2479-2497.

44. Gopalakrishnan, S.G., Roy, S.B. and Avissar, R.: 2000, An evaluation of the scale at which topographical features affect the convective boundary layer using large eddy simulations, $J$. Atmos. Sci. 57, 334-351.

45. Gopalakrishnan, S.G. and Avissar, R.: 2000, An LES study of the impacts of land surface heterogeneity on dispersion in the convective boundary layer, J. Atmos. Sci. 57, 352-371.

46. Roy, S.B., Avissar, R.: 2000, Scales of response of the convective boundary layer to land surface heterogeneity, J. Geophys. Res. Lett. 27, 533-536.

47. Wang, J., Bras, R.L. and Eltahir, E.A.B.: 1996, A stochastic linear theory of mesoscale circulation induced by the thermal heterogeneity of the land surface, J. Atmos. Sci. 53, 3349-3366.

48. Lynn, B.H., Rind, D. and Avissar, R.: 1995, The importance of subgrid-scale mesoscale circulations generated by landscape heterogeneity in general circulation models (GCMs), $J$. Climate 8, 191-205.

49. Pielke, R.A., Zeng, X., Lee, T.J. and Dalu, G.A.: 1997, Mesoscale fluxes over heterogeneous flat landscapes for use in larger scale models, J. Hydrol. 190, 317-336.

50. Cassano, J.L. and Parish, T.R.: 2000, An analysis of the nonhydrostatic dynamics in numerically simulated Antarctic katabatic flows, J. Atmos. Sci. 57, 891-898.

51. Rõõm, R. and Männik, A.: 1999, Responses of different nonhydrostatic, pressure-coordinate models to orographic forcing, J. Atmos. Sci. 56, 2553-2570.

52. Sun, W.-Y.: 1984, Numerical analysis for hydrostatic and nonhydrostatic equations of inertialinternal gravity waves, Mon. Wea. Rev. 112, 259-268.

53. Smith, R.B.: 1989, Hydrostatic air-flow over mountains, Adv. Geophys. 31, 1-41. 
54. Thunis, P. and Clappier, A.: 2000, Formulation and evaluation of a nonhydrostatic mesoscale vorticity model (TVM), Mon. Wea. Rev. 128, 3236-3251.

55. Seman, C.J.: 1994, A numerical study on nonlinear nonhydrostatic conditional symmetric instability in a convectively unstable atmosphere, J. Atmos. Sci. 51, 1352-1371.

56. Donner, L.J., Seman, C.J., Hemler, R.S. and Fan, S.: 2001, A cumulus parameterization including mass fluxes, convective vertical velocities, and mesoscale effects: Thermodynamic and hydrological aspects in a general circulation model, J. Climate 14, 3444-3463.

57. Molemaker, M.J. and Dijkstra, H.: 2000, Stability of a cold core eddy in the presence of convection: Hydrostatic versus nonhydrostatic modeling, J. Phys. Oceanogr. 30, 475-494.

58. Cotton, W.R. and Anthes, R.A.: 1989, Storm and Cloud Dynamics. Academic Press, San Diego, CA, 883 pp.

59. Song, J.L., Pielke, R.A., Arritt, R.W. and Kessler, R.C.: 1985, A method to determine nonhydrostatic effects within subdomains in a mesoscale model, J. Atmos. Sci. 42, 2110-2119.

60. Dalu, G.A., Pielke, R.A., Baldi, M. and Zeng, X.: 1996, Heat and momentum fluxes induced by thermal inhomogeneities, J. Atmos. Sci. 53, 3286-3302.

61. Stull, R.B.: 1988, An Introduction to Boundary Layer Meteorology, Kluwer Academic Publishers, Dordrecht.

62. LePage, W.R.: 1961, Complex Variables and the Laplace Transform for Engineers, Dover Publications.

63. Crook, N.A. and Klemp, J.B.: 2000, Lifting by convergence lines, J. Atmos. Sci. 57, 873-890.

64. André, J.-C., Goutorbe, J.P., Schmugge, T. and Perrier, A.: 1989b, HAPEX-MOBILHY: Results from a large-scale field experiment. In: A. Rango, (ed.), Remote Sensing and Large-Scale Global Processes, Wallingford, UK, International Association of Hydrological Sciences, pp. 13-20.

65. Dalu, G.A. and Pielke, R.A.: 1993, Vertical heat fluxes generated by mesoscale atmospheric flow induced by thermal inhomogeneities in the PBL, J. Atmos. Sci. 50, 919-926.

66. Rotunno, R. and Klemp, J.: 1982, The influence of the shear-induced pressure gradient on thunderstorm motion, Mon. Wea. Rev. 110, 136-151.

67. Weidman, S.T. and Pielke, R.A.: 1983, A more accurate method for the numerical solution of nonlinear partial differential equations, J. Comput. Phys. 49, 342-348. 